\title{
Information or Prices, Which Is Most Powerful in Increasing Consumer Demand for Organic Vegetables?
}

\author{
Sinne Smed ${ }^{1} \&$ Laura M. Andersen ${ }^{1}$ \\ ${ }^{1}$ Institute of Food and Resource Economics, University of Copenhagen, Denmark \\ Correspondence: Sinne Smed, Institute of Food and Resource Economics, Rolighedsvej 25, DK-1958 \\ Frederiksberg C, Denmark. Tel: 45-35-336-849. E-mail: ss@foi.ku.dk
}

Received: September 27, 2012

Accepted: November 5, $2012 \quad$ Online Published: November 19, 2012

doi:10.5539/ibr.v5n12p175

URL: http://dx.doi.org/10.5539/ibr.v5n12p175

\begin{abstract}
Based on a unique and very detailed panel dataset covering consumption of organically and conventionally produced vegetables in the years 2005 - 2007, we examine the effects of information about positive health effects of consuming organic vegetables and information about negative health effects of consuming conventional vegetables on demand for organic foods for six different segments of Danish households. Three of these segments are positive towards organics whereas the remaining three segments are negative or indifferent. Using the double hurdle model we estimate partial effects of both directly and indirectly obtained information as well as prices. The results show, that there are larger effects of information for households where the information is in accordance with initial knowledge and attitudes, hence the positive segments react more to information whereas the negative segments react more to prices. "New" consumers can be persuaded to buy organic vegetables by providing information about the negative health effects of consuming conventional vegetables since it increases the probability of an organic purchase. Once consumers have entered the organic marked for vegetables, information that link health and the consumption of organic vegetables will increase consumption. The results are important for firms and producers who want to successfully target information to different consumer groups with the aim of increasing the market share for organic food.
\end{abstract}

Keywords: consumer response to information, direct and indirect information, double hurdle model, organic foods, panel data

\section{Introduction}

Some decades ago, organic foods were aimed at a small dedicated group of consumers with idealistic ideas who bought organic foods in speciality stores. Therefore the consumption of organic foods was low in Denmark with a general market share of organic foods less than 1 - 2 per cent (Hamm \& Michelsen, 1996). The entry of the state endorsed and state controlled national organic label in 1989, and government subsidies for organic production together with advisory services to organic farmers during the conversion period, initiated a supply driven demand for organic foods (Hamm \& Michelsen, 1996; Økologisk Landsforening, 2012). Finally, when supermarkets in 1993 initiated intensive marketing of organic products and lowered prices of organic products by 15 to 20 per cent, demand increased considerably and today organic foods constitute around 7.5 per cent of the total budget for food (Hamm \& Michelsen, 1996; Økologisk Landsforening, 2012). The expansion of supply to include supermarkets and discount stores has introduced new consumers to the organic market (Richter, 2008; Padel et al., 2009; Lund et al., 2012; Gottschalk \& Leistner, 2012). This entails, that the traditional image of the organic consumer as belonging to a very dedicated segment needs to be revised and expanded to include further less dedicated organic consumer profiles (Midmore et al., 2005; Hughner et al., 2007; Gottschalk \& Leistner, 2012). It is important to identify differences in terms of attitudes to organics and food consumption in general between this new type of organic consumer and the traditional dedicated consumer. Studying differences in demand between lifestyle- and attitude-based consumer segments can give insight in the attitudes and motivations behind specific behaviour of various consumer groups (Nie \& Zepeda, 2011). This might be helpful in on order to successfully target marketing campaigns.

Despite that the Danish organic label is recognized and trusted by almost all Danish consumers and that it relies on well-defined properties of the organic standard (IFOAM, 2005) the organic attribute is a credence attribute. This implies that information about the attribute is asymmetric and that consumers have no possibilities to 
control, taste or see whether the organic product they buy contains the expected characteristics (Nelson, 1970; Darby \& Karni, 1973). The subjective nature of credence goods implies that the perceived quality of the product in question might change due to incoming new information (Verbeke, 2005). Our aim in this study is to estimate the effect of exogenous factors like information and prices on the demand for organic vegetables. As our analysis is based on a comprehensive panel dataset, including actual purchases, stated attitudes and actual information indexes, we are able to divide the panel into six different consumer segments and to estimate the effect of both prices and information for each of these. We use the number of newspaper articles to account for the level of exogenous information and divide it into two types of information; "negative" information about incidents of pesticides in conventional vegetables and "positive" information that link health and consumption of organic vegetables. Consumers receive information, process it and then potentially change behaviour if it is preferable for them to do so. Processing information is not costless, and it might be rational for consumers to ignore information, due to that the expected benefits from processing the information are smaller than the expected costs (Swinnen et al., 2005; McClusky \& Swinnen, 2004). The more the information that the consumer receive differ from his initial believes, the larger is the processing costs and the more information that the consumer already have, the smaller is the benefit from new incoming information (McClusky \& Swinnen, 2004). We therefore expect different reaction patterns from the six different consumer segments since they differ substantially in their initial knowledge about organic products and production methods and in their initial perceptions of what constitutes the organic attribute in particular and in their health orientation in general.

Knowing how to reach different consumer segments by information is important in marketing campaigns aiming at increasing organic food consumption (Nie \& Zepeda, 2011). Furthermore, as our data comprise detailed information about the consumers' media habits our study contributes to the literature by weighting the index according to whether the article is published in a newspaper that this particular household read regularly and to compare this type of "direct" information with the effect of "indirect" information based on information indices that are not weighted according to readership and as such represent disseminated information. Furthermore we use the double hurdle model in the analysis, which introduces the possibility that the decision to buy organic food is a two-step decision. The first decision is whether to be an organic purchaser or not (participation decision) and the second step is, conditional on being an organic purchaser, the amount to purchase (consumption decision).

\section{Conceptual Model}

As in Smed (2012) and following Heiman and Lowengart (2008) we take outset in the household production model by Becker (1965) and assume that households get utility from meals which they prepare from market goods (e.g. vegetables, oil, etc). In this paper we focus on the differences in the utility of using conventional versus organic vegetables when preparing meals, and assume that the input of other goods are unaffected by this choice. Since consumers' choice of food commodities is mainly based on differences in health and sensory characteristics (see, e.g. Holm \& Kildevang, 1996; Pearson et al., 2011), we let individual utility be given as (subscript $t$ for time is suppressed for ease of notation):

$$
U_{i}=u_{i}\left(s_{i}\left(y_{i}\right), h_{i}\left(y_{i}, I_{i} .\left(\theta_{i}\right)\right)\right)
$$

Where $i$ denotes the individual household, $y_{i j}$ is a vector of quantities of organic or conventional products (determined by $j$ where $j \in($ org, conv $))$ and $y_{i}=\left(y_{i, o r g}, y_{i, \text { conv }}\right)$ therefore is a vector of quantities of both organic and conventional products consumed by household $i$. The functions $s_{i}(\cdot)$ and $h_{i}(\cdot)$ measure the perceived content of sensory qualities (including taste, texture and other attributes) and health respectively. $I_{i}=\left(I_{i, o r g}\right.$, $I_{i, \text { conv }}$ ) denotes a vector of exogenous information about organic and conventional products that the individual consumer receives about the health risks and benefits of consuming either the conventional or organic version of this particular product. The utility value of this exogenous information depends on initial knowledge and attitudes $\theta_{i}$. This is based on Swinnen et al., (2005) and McCluskey \& Swinnen (2007), who state that consumers prefer to inform themselves only up to a point where the marginal increase in utility from additional information is equal to the marginal cost, including opportunity costs, of using resources to read and process the particular news story. Consumers may have different attitudes towards health and sensory characteristics, and may therefore draw different conclusions even if they have the same level of initial knowledge. For a consumer with a specific attitude or ideology, processing a media story with a divergent ideology or attitude, may provide additional costs to the consumer in terms of disutility. This means that costs and benefits of processing news stories vary between consumers, depending on their initial level of knowledge, their attitudes and other characteristics. 
This leads to the following maximization problem for consumer $i$ :

$$
\begin{aligned}
\max _{y_{i}} U_{i}=u_{i}\left(s_{i}\left(y_{i, \text { org }}, y_{i, \text { conv }}\right), h_{i}\left(y_{i, \text { org }}, y_{i, \text { conv }}, I_{i, \text { org }}\left(\theta_{i}\right), I_{i, \text { conv }}\left(\theta_{i}\right)\right)\right) \\
\text { s.t. } X_{i}=\sum_{j \in\{\text { org, conv }\}} p_{j} y_{i j}
\end{aligned}
$$

Where $X_{i}$ is the budget allocated to the category of interest (e.g. vegetables) and $p_{j}$ is the price of the organic and the conventional variety of this category respectively. From (2) and from the additional assumption of additive utility of sensory and health attributes; $U_{i}=\pi_{i s} s_{i}()+.\pi_{i h} h_{i}($.$) where \pi_{i s}$ and $\pi_{i h}$ are the marginal utilities of sensory and health qualities respectively we get the marginal rate of substitution between organic and conventional as:

$$
\frac{M U_{i, \text { org }}}{M U_{i, \text { conv }}}=\frac{\pi_{i s} \frac{\partial s_{i}(\cdot)}{\partial y_{i, \text { org }}}+\pi_{i h} \frac{\partial h_{i}(\cdot)}{\partial y_{i, \text { org }}}}{\pi_{i s} \frac{\partial s_{i}(\cdot)}{\partial y_{i, \text { conv }}}+\pi_{i h} \frac{\partial h_{i}(\cdot)}{\partial y_{i, \text { conv }}}}=\frac{p_{\text {org }}}{p_{\text {conv }}}
$$

where $M U_{i, o r g}$ and $M U_{i, c o n v}$ are the marginal utilities from the consumption of the organic and conventional variety. The content of the sensory attributes $\partial s_{i}(\cdot) / \partial y_{i, o r g}$ and $\partial s_{i}(\cdot) / \partial y_{i, c o n v}$ in the organic and the conventional variety respectively do not depend on the level of information, only on the level of $y_{i, o r g}$ and $y_{i, c o n v}$, but may vary between households. The content of the health attribute $\partial h_{i}(\cdot) / \partial y_{i, \text { conv }}$ and $\partial h_{i}(\cdot) / \partial y_{i, \text { org }}$ depend not only on the level of $y_{i, o r g}$ and $y_{i, \text { conv }}$ but also on the values of $I_{\text {org }}\left(\theta_{i}\right)$ and $I_{\text {conv }}\left(\theta_{i}\right)$. The consumers form expectations about the actual content of this attribute in the products dependent on obtained information. Whenever consumers read an article about e.g. the incidence of pesticides in the conventional variety, then, dependent on initial knowledge and attitudes, the consumer may choose to process the information and perhaps change perception about how healthy the conventional variety is relative to the organic, hence $\partial h_{i}(\cdot) / \partial y_{i, c o n v}$ may decrease compared to $\partial h_{i}(\cdot) / \partial y_{i, o r g}$. For unchanged relative market prices of the organic and conventional varieties, a decreasing marginal utility of the conventional variety will lead to an increased organic consumption in order to fulfil the optimization criterion (3). The opposite happens when the consumer read positive information about the healthiness of the organic varieties; hence both negative information about conventional varieties and positive information about organic varieties are therefore expected to increase the probability of choosing the organic variety as well as increasing the level of consumption.

\section{Segmentation and Expected Reactions to Information}

In the current paper we operate with the six different types (segments) of organic consumers constructed in Lund et al. (2012). Initially the segments are defined based on focus group interviews, in depth interviews and observations of consumers' shopping behaviour. The same segments are re-found using latent class analysis (LCA), on answers to a questionnaire issued to approximately 2000 consumers in 2007 . We also have monthly observations of purchased staples during several years for the respondents to the questionnaires (Note 1). In Lund et al. (2012) the segments are identified according to their general food involvement, (Note 2) price sensitivity, (Note 3) trust in organic production, (Note 4) perception of the intrinsic qualities of organic foods and altruistic concerns in food provisioning (Note 5). The segmentation divide the Danish population in two equally sized parts; one half with positive attitude towards organics and another half which are either indifferent or sceptical. The positive segments represent 87 per cent of private organic purchases. The segments also differ in their general level of concern about pesticide residues and additives, in their capability of eating healthy as well as in their knowledge of and perceptions about organic food and in the importance the put on prices (see table 1 and 2).

Generally it is assumed that the higher the level of concern about pesticides and additives the stronger is the reaction to both negative and positive information due to an increased benefit from the information. Furthermore the stronger the capability of eating healthy the easier it will be to react to both types of information since it lowers the cost of reacting to the information. As mentioned in the introduction, initial perceptions are likewise assumed to have an influence on the expected reaction to information. Hence consumers that perceive organic products are healthier than conventional products are assumed to react more to information that link health and consumption of organics and consumers that perceive there are fewer pesticides and medicine residues in organic 
products is assumed to react more to pesticide information. The strength of the reaction is assumed to diminish with the level of the perceived knowledge due to diminishing marginal return to information (Swinnen et al., 2005; McClusky \& Swinnen, 2004). Likewise, stated knowledge of organic production methods and products (measured by the question "I don't know a lot about organic products/production") are assumed to decrease the reaction to information due to this diminishing marginal effect of information.

Table 1. Distribution of answers to questions about food and health in general

\begin{tabular}{|c|c|c|c|c|c|}
\hline & \multicolumn{3}{|c|}{ General level of concern } & \multicolumn{2}{|c|}{ Capability of eating healthy } \\
\hline & $\begin{array}{l}\text { Agree with "It is } \\
\text { important that my } \\
\text { food does not } \\
\text { have additives" }\end{array}$ & $\begin{array}{l}\text { Often or very } \\
\text { often worried } \\
\text { about pesticide } \\
\text { residues in food }\end{array}$ & $\begin{array}{l}\text { Disagree with "I } \\
\text { seldom think about } \\
\text { whether } \\
\text { the food I eat is } \\
\text { healthy" }\end{array}$ & $\begin{array}{l}\text { Disagree with "I } \\
\text { do not feel up to } \\
\text { learning about } \\
\text { how to eat } \\
\text { healthily" }\end{array}$ & $\begin{array}{l}\text { Agree with } \\
\text { "Healthy food } \\
\text { usually tastes } \\
\text { better than } \\
\text { unhealthy food" }\end{array}$ \\
\hline Convinced & $88 \%$ & $67 \%$ & $85 \%$ & $88 \%$ & $60 \%$ \\
\hline Positive and food involved & $62 \%$ & $46 \%$ & $82 \%$ & $88 \%$ & $52 \%$ \\
\hline Positive and convenient & $54 \%$ & $44 \%$ & $67 \%$ & $63 \%$ & $39 \%$ \\
\hline Product focussed & $52 \%$ & $35 \%$ & $69 \%$ & $70 \%$ & $40 \%$ \\
\hline Indifferent & $34 \%$ & $28 \%$ & $38 \%$ & $44 \&$ & $27 \%$ \\
\hline Sceptics & $52 \%$ & $39 \%$ & $61 \%$ & $68 \%$ & $39 \%$ \\
\hline TOTAL & $58 \%$ & $43 \%$ & $70 \%$ & $73 \%$ & $44 \%$ \\
\hline
\end{tabular}

Source: Own calculations based on the segments' answers to the questions from the CONCEPTS questionnaire (For more on the questionnaire see Andersen, 2009).

Table 2. Distribution of answers to questions about perception and knowledge about organics and importance of prices

\begin{tabular}{|c|c|c|c|c|c|}
\hline & \multicolumn{2}{|c|}{ Initial perception of organic products } & \multirow{2}{*}{$\begin{array}{l}\text { Knowledge } \\
\text { About organics } \\
\text { Disagree with "I } \\
\text { don't know a great } \\
\text { deal about organic } \\
\text { products/ } \\
\text { production" }\end{array}$} & \multicolumn{2}{|c|}{$\begin{array}{l}\text { Price sensitivity, general and for } \\
\text { organics in particular }\end{array}$} \\
\hline & $\begin{array}{l}\text { Agree with"I think } \\
\text { there are fewer } \\
\text { pesticides and } \\
\text { medicine residues in } \\
\text { organic products" }\end{array}$ & $\begin{array}{l}\text { Agree with "I think that } \\
\text { organic products are } \\
\text { healthier for me and my } \\
\text { family than } \\
\text { conventional products" }\end{array}$ & & $\begin{array}{l}\text { Disagree } \\
\text { with "Price is } \\
\text { more } \\
\text { important } \\
\text { than quality" }\end{array}$ & $\begin{array}{l}\text { Disagree with "I } \\
\text { usually do not buy } \\
\text { organic products } \\
\text { because the price } \\
\text { is too high" }\end{array}$ \\
\hline Convinced & $94 \%$ & $100 \%$ & $83 \%$ & $83 \%$ & $58 \%$ \\
\hline Positive and food involved & $89 \%$ & $87 \%$ & $63 \%$ & $72 \%$ & $27 \%$ \\
\hline Positive and convenient & $86 \%$ & $83 \%$ & $55 \%$ & $49 \%$ & $24 \%$ \\
\hline Product focussed & $59 \%$ & $32 \%$ & $27 \%$ & $58 \%$ & $10 \%$ \\
\hline Indifferent & $40 \%$ & $16 \%$ & $16 \%$ & $17 \%$ & $3 \%$ \\
\hline Sceptics & $41 \%$ & $12 \%$ & $28 \%$ & $46 \%$ & $3 \%$ \\
\hline TOTAL & $71 \%$ & $57 \%$ & $46 \%$ & $58 \%$ & $21 \%$ \\
\hline
\end{tabular}

Source: Own calculations based on the segments' answers to the questions from the CONCEPTS questionnaire (For more on the questionnaire see Andersen, 2009).

Combining the generic profiles of the segments, as described in Lund et al. (2012) with the answers to the questions presented in table 1 and table 2 will give a hint about the expected reactions to information for the different segments. The negative segments; the product focussed, the indifferent and the sceptics have a rather low generic health orientation whereas the positive segments; the convinced, the positive and food involved and the positive and convenient have a high generic health orientation (Lund et al., 2012). Despite the low health orientation of the negative segments the majority of the households in each segment, according to table 1, worry about additives, think about whether the food they eat is healthy and want to learn how to eat healthily. An exception here is the indifferent. The convinced and to some extent the positive and food involved however single themselves out by having increased health awareness and to some extent a larger concern about pesticide residues in food. On basis of that we might expect a rather large reaction to information from all segments apart from the indifferent.

What splits up the respondents in terms of expected reaction to information is their perceptions of the organic products. According to Lund et al. (2012) the positive segments are all characterised by having high trust in the intrinsic qualities of organic foods and high trust in organic production even though only some of the benefits attributed to organic consumption are commonly recognized by the positive and food involved. The positive and convenient have a rather low food involvement. The product focussed have most of their attention directed towards the specific attributes of food products that can be assessed while shopping, so they are not concerned 
with the production processes behind their products. Nevertheless they are concerned with the adverse effects of conventional agricultural production. The sceptics are characterised by having low trust in the intrinsic qualities of organic foods and in organic production whereas the two other "negative" segments are characterised by being indifferent to these issues. All three segments have no active search processes to look for organic products and for the two latter segments organic purchases are mainly coincidental, whereas the product focussed occasionally purchase organics for taste reasons.

From table 2 we see that the three positive segments perceive organic foods to contain fewer pesticides and medicine residues and to be healthier for them and their families. Hence largest reaction is expected to be from the positive segments since the information that they receive is in accordance with their initial believes which lower information processing cost. However, due to decreasing marginal benefit of information acquisition the perception that organic foods contains fewer pesticides and additives will only increase the reaction up to a certain point as knowledge of organic production and production methods might lower the expected reaction.In terms of expected reaction to prices the convinced generally devote considerable resources in terms of both time and money to find the organic variety instead of a similar conventional product, whereas the two other positive segments use fewer resources to obtain organic products. The positive and food involved are willing to pay extra for the organic attribute as long as they expect it to provide extra quality. The positive and convenient try to avoid pricy products; hence they are expected to have higher price elasticity than any of the two other positive segments. We expect the convinced to have a rather low price elasticity, especially since, according to table 2 two thirds of them are not limited in their organic purchases because of the price. Based on the above discussion the expected reactions to prices and to the two types of information for each segment is summarized in table 3 .

Table 3. Expected reaction to information and prices for the different segments

\begin{tabular}{llll} 
& \multicolumn{2}{l}{ Information about: } & Relative prices \\
\cline { 2 - 4 } & $\begin{array}{l}\text { Pesticides in conventional } \\
\text { vegetables }\end{array}$ & Organic is healthier & Low \\
\hline Convinced & Medium & Medium to high & Medium \\
Positive and food involved & High & Medium & High \\
Positive and convenient & Medium to high & Medium to low & Low to medium \\
Product focused & Medium & Low to medium & High \\
Indifferent & Low & Low & High \\
Sceptics & Low & Low & \\
\hline
\end{tabular}

\section{Data}

The data we use in our estimations are provided by GfK ConsumerTracking Scandinavia (Note 6). About 20 per cent of the households leave the panel each year and are replaced by a similar type of household (Note 7). For each shopping trip the diary keeper reports purchases of foods and other staples, including the date and time of the day and total expenditure on the trip. For almost all goods in all periods the value and quantity of the product is registered as well as if the food is organically or conventionally produced. Vegetables are furthermore registered by type of vegetables. We use data on vegetable consumption for the period 2005 to 2007 and aggregate to monthly observations. Aggregate Törnquist price indices (Törnquist, 1936) are constructed for conventional and organic vegetables respectively. Additional to the purchase data, the households complete an annual questionnaire on their background, including social and demographic characteristics (family size, age, level of education, region, income etc.) media habits (e.g. preferred newspapers and magazines and frequency of reading) and several attitude questions. The mean and standard deviations of the variables that are used in the estimations are shown in table 4 below. Following e.g. Piggott and Marsh (2004), Kalaitzandonakes et al. (2004), Adhikari et al. (2006), Lusk (2004), Schmidt and Kaiser (2003) and Tonso and Olynk (2010) we base our information index on articles (unweighted or weighted by readership) in the popular press.

Information about pesticides in conventional vegetables and information that link consumption of organic vegetables with health are found by an extensive search in the database Infomedia, which covers articles in all Danish newspapers. The index on pesticides in conventional vegetables is based on search words: "Pesticide/crop spray/poison" in combination with "vegetables". The health index is constructed using search words: "Organic vegetables" in combination with "healthy". The constructed indices account in principle for positive and negative information similar to the analyses by e.g. Verbeke \& Ward (2001) who analyse the effect of publicity in TV about BSE together with advertising expenditure for beef consumption or more recently Tonsor et al. (2010) who analyse the effect of different types of positive and negative information on food consumption. Furthermore, following Smed (2012), we construct two types of indices; an index aggregated of all 
articles in all newspapers that account for indirect information (Note 8) and an index with direct information where the index is weighted according to whether the article appear in a newspaper that is read by this particular household. The weighting is done by first making specific indices for each newspaper, and then secondly to match these with the households that read the particular newspaper in question (Note 9). This leads to individual information indices for each household. As both the direct and indirect information indices are based on absolute numbers, we subtract the number of articles in the direct information index from the indirect information index to avoid double counting. Furthermore we account for the lagged effect of information by introducing one lag in our model to account for both lasting and diminishing effect. (Note 10)

Table 4. Mean (and std.dev.) of variables used in the regression (averaged over the years 2005 - 2007)

\begin{tabular}{|c|c|c|c|c|c|c|c|}
\hline & Convinced & $\begin{array}{l}\text { Positive and } \\
\text { food involv. }\end{array}$ & $\begin{array}{l}\text { Positive and } \\
\text { convenient }\end{array}$ & $\begin{array}{l}\text { Product } \\
\text { focused }\end{array}$ & Indifferent & Sceptics & All \\
\hline$\%$ of the sample & 12.8 & 24.4 & 13.6 & 30.0 & 8.7 & 10.5 & 100 \\
\hline Organic quantity share, vegetables $(0-1)$ & $\begin{array}{l}0.158 \\
(0.266)\end{array}$ & $\begin{array}{l}0.072 \\
(0.180)\end{array}$ & $\begin{array}{l}0.081 \\
(0.199)\end{array}$ & $\begin{array}{l}0.027 \\
(0.108)\end{array}$ & $\begin{array}{l}0.021 \\
(0.098)\end{array}$ & $\begin{array}{l}0.014 \\
(0.075)\end{array}$ & $\begin{array}{l}0.061 \\
(0.174)\end{array}$ \\
\hline $\begin{array}{l}\text { Monthly expenditure on fruit } \\
\text { and vegetables (DKK/pers) }\end{array}$ & $\begin{array}{l}177.45 \\
(397.06)\end{array}$ & $\begin{array}{l}155.11 \\
(319.66)\end{array}$ & $\begin{array}{l}137.58 \\
(298.65)\end{array}$ & $\begin{array}{l}128.33 \\
(262.59)\end{array}$ & $\begin{array}{l}101.87 \\
(225.19)\end{array}$ & $\begin{array}{l}119.20 \\
(245.59)\end{array}$ & $\begin{array}{l}139.80 \\
(300.78)\end{array}$ \\
\hline Age of main buyer (years) & $\begin{array}{l}60.8 \\
(12.8)\end{array}$ & $\begin{array}{l}57.1 \\
(12.7)\end{array}$ & $\begin{array}{l}58.8 \\
(14.8)\end{array}$ & $\begin{array}{l}58.4 \\
(13.8)\end{array}$ & $\begin{array}{l}61.7 \\
(13.1)\end{array}$ & $\begin{array}{l}60.8 \\
(12.9)\end{array}$ & $\begin{array}{l}59.1 \\
(13.5)\end{array}$ \\
\hline \multicolumn{8}{|l|}{ Binary or categorical variables } \\
\hline $\begin{array}{l}\text { Purchase frequency of organic vegetables }{ }^{1} \\
(0-1)\end{array}$ & $\begin{array}{l}0.41 \\
(0.49)\end{array}$ & $\begin{array}{l}0.26 \\
(0.44)\end{array}$ & $\begin{array}{l}0.24 \\
(0.43)\end{array}$ & $\begin{array}{l}0.12 \\
(0.32)\end{array}$ & $\begin{array}{l}0.09 \\
(0.28)\end{array}$ & $\begin{array}{l}0.07 \\
(0.26)\end{array}$ & $\begin{array}{l}0.20 \\
(0.40)\end{array}$ \\
\hline Children between 0 and 6 years & $\begin{array}{l}0.06 \\
(0.23)\end{array}$ & $\begin{array}{l}0.09 \\
(0.28)\end{array}$ & $\begin{array}{l}0.05 \\
(0.22)\end{array}$ & $\begin{array}{l}0.08 \\
(0.27)\end{array}$ & $\begin{array}{l}0.05 \\
(0.21)\end{array}$ & $\begin{array}{l}0.05 \\
(0.21)\end{array}$ & $\begin{array}{l}0.07 \\
(0.25)\end{array}$ \\
\hline Children between 7 and 14 years & $\begin{array}{l}0.08 \\
(0.27)\end{array}$ & $\begin{array}{l}0.10 \\
(0.29)\end{array}$ & $\begin{array}{l}0.14 \\
(0.34)\end{array}$ & $\begin{array}{l}0.09 \\
(0.28)\end{array}$ & $\begin{array}{l}0.09 \\
(0.28)\end{array}$ & $\begin{array}{l}0.12 \\
(0.33)\end{array}$ & $\begin{array}{l}0.10 \\
(0.30)\end{array}$ \\
\hline Adolescents betw. 15 and 20 years & $\begin{array}{l}0.08 \\
(0.27)\end{array}$ & $\begin{array}{l}0.10 \\
(0.30)\end{array}$ & $\begin{array}{l}0.11 \\
(0.32)\end{array}$ & $\begin{array}{l}0.08 \\
(0.27)\end{array}$ & $\begin{array}{l}0.07 \\
(0.26)\end{array}$ & $\begin{array}{l}0.12 \\
(0.33)\end{array}$ & $\begin{array}{l}0.09 \\
(0.29)\end{array}$ \\
\hline \multicolumn{8}{|l|}{ Further education ${ }^{2}$} \\
\hline None & $\begin{array}{l}0.13 \\
(0.34)\end{array}$ & $\begin{array}{l}0.17 \\
(0.38)\end{array}$ & $\begin{array}{l}0.22 \\
(0.42)\end{array}$ & $\begin{array}{l}0.26 \\
(0.44\end{array}$ & $\begin{array}{l}0.37 \\
(0.48)\end{array}$ & $\begin{array}{l}0.27 \\
(0.44)\end{array}$ & $\begin{array}{l}0.23 \\
(0.42)\end{array}$ \\
\hline Vocational & $\begin{array}{l}0.39 \\
(0.49)\end{array}$ & $\begin{array}{l}0.36 \\
(0.48)\end{array}$ & $\begin{array}{l}0.36 \\
(0.48)\end{array}$ & $\begin{array}{l}0.38 \\
(0.49\end{array}$ & $\begin{array}{l}0.38 \\
(0.49)\end{array}$ & $\begin{array}{l}0.38 \\
(0.48)\end{array}$ & $\begin{array}{l}0.37 \\
(0.48)\end{array}$ \\
\hline Short & $\begin{array}{l}0.19 \\
(0.40)\end{array}$ & $\begin{array}{l}0.15 \\
(0.36)\end{array}$ & $\begin{array}{l}0.15 \\
(0.36)\end{array}$ & $\begin{array}{l}0.15 \\
(0.36\end{array}$ & $\begin{array}{l}0.12 \\
(0.32)\end{array}$ & $\begin{array}{l}0.19 \\
(0.39)\end{array}$ & $\begin{array}{l}0.16 \\
(0.37)\end{array}$ \\
\hline Medium & $\begin{array}{l}0.22 \\
(0.41)\end{array}$ & $\begin{array}{l}0.25 \\
(0.43)\end{array}$ & $\begin{array}{l}0.20 \\
(0.40)\end{array}$ & $\begin{array}{l}0.17 \\
(0.38\end{array}$ & $\begin{array}{l}0.09 \\
(0.29)\end{array}$ & $\begin{array}{l}0.14 \\
(0.35)\end{array}$ & $\begin{array}{l}0.19 \\
(0.39)\end{array}$ \\
\hline Long & $\begin{array}{l}0.07 \\
(0.25)\end{array}$ & $\begin{array}{l}0.07 \\
(0.25)\end{array}$ & $\begin{array}{l}0.07 \\
(0.25)\end{array}$ & $\begin{array}{l}0.04 \\
(0.19\end{array}$ & $\begin{array}{l}0.04 \\
(0.19)\end{array}$ & $\begin{array}{l}0.02 \\
(0.15)\end{array}$ & $\begin{array}{l}0.05 \\
(0.22)\end{array}$ \\
\hline \multicolumn{8}{|l|}{ Urbanization } \\
\hline Capital & $\begin{array}{l}0.31 \\
(0.46)\end{array}$ & $\begin{array}{l}0.23 \\
(0.42)\end{array}$ & $\begin{array}{l}0.24 \\
(0.42)\end{array}$ & $\begin{array}{l}0.19 \\
(0.39)\end{array}$ & $\begin{array}{l}0.21 \\
(0.40)\end{array}$ & $\begin{array}{l}0.11 \\
(0.31)\end{array}$ & $\begin{array}{l}0.21 \\
(0.41)\end{array}$ \\
\hline Town & $\begin{array}{l}0.27 \\
(0.44)\end{array}$ & $\begin{array}{l}0.37 \\
(0.48)\end{array}$ & $\begin{array}{l}0.38 \\
(0.48)\end{array}$ & $\begin{array}{l}0.32 \\
(0.47)\end{array}$ & $\begin{array}{l}0.30 \\
(0.46)\end{array}$ & $\begin{array}{l}0.36 \\
(0.48)\end{array}$ & $\begin{array}{l}0.33 \\
(0.47)\end{array}$ \\
\hline Rural & $\begin{array}{l}0.42 \\
(0.49)\end{array}$ & $\begin{array}{l}0.40 \\
(0.49)\end{array}$ & $\begin{array}{l}0.38 \\
(0.49)\end{array}$ & $\begin{array}{l}0.49 \\
(0.50)\end{array}$ & $\begin{array}{l}0.49 \\
(0.50)\end{array}$ & $\begin{array}{l}0.53 \\
(0.50)\end{array}$ & $\begin{array}{l}0.45 \\
(0.50)\end{array}$ \\
\hline \multicolumn{8}{|l|}{ Income quartiles ${ }^{3}$} \\
\hline $0-25 \%$ & $\begin{array}{l}0.34 \\
(0.48)\end{array}$ & $\begin{array}{l}0.30 \\
(0.46)\end{array}$ & $\begin{array}{l}0.38 \\
(0.48)\end{array}$ & $\begin{array}{l}0.36 \\
(0.48)\end{array}$ & $\begin{array}{l}0.53 \\
(0.50)\end{array}$ & $\begin{array}{l}0.38 \\
(0.48)\end{array}$ & $\begin{array}{l}0.36 \\
(0.48)\end{array}$ \\
\hline $25-75 \%$ & $\begin{array}{l}0.42 \\
(0.49)\end{array}$ & $\begin{array}{l}0.41 \\
(0.49)\end{array}$ & $\begin{array}{l}0.43 \\
(0.49)\end{array}$ & $\begin{array}{l}0.41 \\
(0.49)\end{array}$ & $\begin{array}{l}0.32 \\
(0.47)\end{array}$ & $\begin{array}{l}0.44 \\
(0.50)\end{array}$ & $\begin{array}{l}0.41 \\
(0.49)\end{array}$ \\
\hline $75-100 \%$ & $\begin{array}{l}0.23 \\
(0.42)\end{array}$ & $\begin{array}{l}0.29 \\
(0.45)\end{array}$ & $\begin{array}{l}0.19 \\
(0.40)\end{array}$ & $\begin{array}{l}0.23 \\
(0.42)\end{array}$ & $\begin{array}{l}0.16 \\
(0.36)\end{array}$ & $\begin{array}{l}0.18 \\
(0.38)\end{array}$ & $\begin{array}{l}0.23 \\
(0.42)\end{array}$ \\
\hline
\end{tabular}

Note: ${ }^{1}$ For the convinced, this implies that $59 \%$ of all obs. consist of a non-purchase of organic vegetables. ${ }^{2}$ Vocational (e.g. carpenter, nursing aide), short education (e.g. policeman, technical educ.), medium education (e.g. nurse, primary school teacher), long education (e.g. university degree). ${ }^{3}$ Originally income is recorded in brackets of DKK 50,000 ( €6,700). These are divided by the number of persons in the household, weighted by the OECD-modified scale i.e. 1 for the first adult, 0.5 for the next adults and 0.3 for children (OECD). Thereafter the panel is divided into income quintiles. $0-25 \%$ comprise the $25 \%$ of the households with the lowest income etc. Due to the discrete nature of the original income brackets it is not possible to obtain the exact quartiles.

Source: Own calculations based on the respondents answers to the annual questionnaire and on reported purchases in the data from GfK-Consumerscan Scandinavia. 


\section{Empirical Model}

Usually zero observations are assumed to represent standard corner solutions in the participating consumers' purchase quantity problem which is captured empirically by the classical Tobit model (Tobin, 1958). The classical assumption in this model is, that zero consumption is only observed when, and only when, the optimal purchase quantity, given current prices and information loadings, is less than or equal to zero. This implies that any variable that increases the probability of non-zero consumption must also increase the mean of positive consumption. In the case of organic consumption this might not be the case as some zero observations might be attributed to some consumers who do not consider organic foods to contain superior health or quality attributes compared to conventionally produced alternatives (Jolly et al., 1989; O'Donovan \& McCarthy, 2002). These consumers' non purchases are attributed, not to economic factors, but to the consumers' perception of the quality of the conventional product (Deaton \& Irish, 1984; Jones, 1992). Other consumers believe that organic products have superior health attributes compared to conventionally grown alternatives (Vindigni et al., 2002; Pearson et al., 2011), but do not purchase them because they think that the price is too high, as price is often an inhibiting factor in organic consumption (Gottschalk \& Leistner, 2011; Pearson et al., 2011

Following Pudney's (1989) double hurdle model, this two-step decision can be written as (where part = participation, non-part $=$ non participation):

$$
U_{i}^{\text {tot }}=D_{i}(\cdot) U_{i}^{\text {part }}(\cdot)+\left(1-D_{i}(\cdot)\right) U_{i}^{\text {non-part }}(\cdot)
$$

Where the two utility expressions are written as:

$$
\begin{gathered}
U_{i}^{\text {part }}(\cdot)=U_{i}^{\text {part }}\left(s_{i}\left(y_{i, \text { org }}, y_{i, \text { conv }}\right), h_{i}\left(y_{i, \text { org }}, y_{i, \text { conv }}, I_{\text {org }}\left(\theta_{i}\right), I_{\text {conv }}\left(\theta_{i}\right)\right) \mid p_{i, \text { conv }} \cdot y_{i, \text { conv }}+p_{i, \text { org }} \cdot y_{i, \text { org }}=X_{i}\right) \\
U_{i}^{\text {non-part }}(\cdot)=U_{i}^{\text {non-part }}\left(s_{i}\left(y_{i, \text { conv }}\right), h_{i}\left(y_{i, \text { conv }}, I_{\text {org }}\left(\theta_{i}\right), I_{\text {conv }}\left(\theta_{i}\right)\right) \mid p_{i, \text { conv }} \cdot y_{i, \text { conv }}=X_{i}\right)
\end{gathered}
$$

$D_{i}(\cdot)=D_{i}\left(I_{\text {org }}\left(\theta_{i}\right), I_{\text {conv }}\left(\theta_{i}\right)\right)$, where $D_{i}$ is an indicator of whether consumer $i$ is a participant at the organic market or not. The utilities are observed with an error and therefore the dummy $D_{i}$ is modelled by the classic binary Probit model where participation is determined by comparing the utility of choosing one alternative to the utility of choosing another alternative.

$$
D_{i t}= \begin{cases}1 & \text { if } U_{i}^{\text {part }}>U_{i}^{\text {non-part }} \\ 0 & \text { if } U_{i}^{\text {part }} \leq U_{i}^{\text {non-part }}\end{cases}
$$

This means that the expected value of $D_{i}$ in equation (4b) represents the probability that a person will choose to participate in the organic market. $D_{i}$ is not determined within the utility maximization mechanism in (2) which implies that the choice between being a market participant or not can be considered to be unconnected with prices and income levels (Pudney, 1989). Hence, it is assumed that, in order to observe positive consumption, two separate hurdles must be passed. The consumer has to decide whether to be a market participant (participation decision) and, conditional on being a market participant, how much to consume (consumption decision). This means that the participation and consumption decisions are allowed to be determined by different sets of parameters (Atkinson et al., 2008).

We wish to investigate how prices and information influence the choice between organic and conventional vegetables. In order to simplify the model we use the quantity share of organic vegetables as our dependent variable, as we would otherwise need to estimate a system of two equation, one for organic and one for conventional. The two decision processes related to organic consumption can be formalized as:

The participation decision:

$$
y_{i 1 t, o r g}^{*}=\alpha^{\prime} w_{i t}+v_{i t}
$$

The consumption decision:

$$
y_{i 2 t, o r g}^{*}=\beta^{\prime} x_{i t}+u_{i t}
$$

where $y_{i l t, \text { org }}^{*}$ is a latent participation indicator, indicating potential participation if $y_{i 1 t, \text { org }}^{*}>0, y_{i 2 t, \text { org }}^{*}$ is latent consumption, indicating consumption of $y_{i 2 t, o r g}^{*}$ if $y_{i 2 t, \text { org }}^{*}>0, w_{i t}$ and $x_{i t}$ are vectors of explanatory variables including information, $\alpha$ and $\beta$ are vectors of parameters and $v_{i t}$ and $u_{i t}$ are idiosyncratic independent 
normally distributed errors. The observed consumption $y_{i t, o r g}$ relates to latent consumption such that:

$$
y_{i t, o r g}= \begin{cases}\beta^{\prime} x_{i t}+u_{i t} & \text { if } y_{i t 1, o r g}^{*}>0 \text { and if } y_{i t 2, o r g}^{*}>0 \\ 0 & \text { otherwise }\end{cases}
$$

where $y_{i t, \text { org }}$ is the $i$ 'th household's observed purchase of organic vegetables. If household $i$ is not a market participant, then $y_{i l t, o r g}^{*}=0$. Under the assumption of independence (Note 11) of the error terms of the participation and the consumption equations and normality of the error term, the likelihood equation becomes (Jones, 1989; Cragg, 1971; Burke, 2009):

$$
L_{i}=\left[1-\Phi\left(\alpha^{\prime} w_{i t}\right)\right]^{I\left(D_{i t}=0\right)}\left[\frac{1}{\sigma_{i t}} \varphi\left(\frac{y_{i t, o r g}-\beta^{\prime} x_{i t}}{\sigma_{i t}}\right) \Phi\left(\alpha^{\prime} w_{i t}\right) / \Phi\left(\frac{\beta^{\prime} x_{i t}}{\sigma_{i t}}\right)\right]^{I\left(D_{i t}=1\right)}
$$

If no separate first hurdle exists, everyone is assumed to participate, i.e. $\Phi\left(\alpha^{\prime} w_{i t}\right)=1 \forall i$ and the model reduces to the Tobit model.. The actual equations estimated are shown below. Note that we use the same set of explanatory variables in the two hurdles, and that separate parameters for the intercept, trends, $t$ and $t^{2}$, prices $(\text { rel_price })_{t}$ ), expenditure (monthly_exp ex $_{i t}$ ) and negative information about pesticides or positive information about health effects, direct as well as indirect, (pest_dir $r_{i t}$, pest_dir $r_{i t-1}$, pest_indir $r_{i t}$, pest_indir $r_{i t-1}$, health_dir $r_{i t}$, health_dir $r_{i t-1}$, health_indir $r_{i t}$ and health_indir $\left.r_{i t-1}\right)$ are estimated for each of the $\overline{6}$ segments ( $s$ account for segment). The effects of socio demographics, socio $_{i}$, are assumed to be the same for the different segments.

The participation decision:

$$
\begin{aligned}
& y_{i 1 t, o r g}^{*}=\sum_{s=1}^{6}\left(\alpha_{0 s}+\delta_{1 s} t+\delta_{2 s} t^{2}+\alpha_{1 s} \text { rel_price }_{t}+\alpha_{2 s} \text { monthly_exp }{ }_{i t}\right) \\
& +\sum_{s=1}^{6}\left(\alpha_{3 s} \text { pest_dir } i_{i t}+\alpha_{4 s} \text { pest_dir } r_{i t-1}+\alpha_{5 s} \text { pest_indir }{ }_{i t}+\alpha_{6 s} \text { pest_indir } r_{i t-1}\right) \\
& +\sum_{s=1}^{6}\left(\alpha_{7 s} \text { health_dir } i_{i t}+\alpha_{8 s} \text { health_dir } i_{i t-1}+\alpha_{9 s} \text { health_indir }{ }_{i t}+\alpha_{10 s} \text { health_indir } i_{i t-1}\right) \\
& +\sum_{k=11}^{23}\left(\alpha_{k} \text { socio }_{i}\right)+c_{1 i}+v_{i t}
\end{aligned}
$$

The consumption decision:

$$
\begin{aligned}
y_{i 2 t, o r g}^{*} & =\sum_{s=1}^{6}\left(\beta_{0 h}+\eta_{1 s} t+\eta_{2 s} t^{2}+\beta_{1 s} \text { rel_price }_{t}+\beta_{2 s} \text { monthly_exp }{ }_{i t}\right) \\
& +\sum_{h=1}^{6}\left(\beta_{3 s} \text { pest_dir } r_{i t}+\beta_{4 s} \text { pest_dir } i_{i t-1}+\beta_{5 s} \text { pest_indir } r_{i t}+\beta_{6 s} \text { pest_indir } r_{i t-1}\right) \\
& +\sum_{h=1}^{6}\left(\beta_{7 s} \text { health_dir } i_{i t}+\beta_{8 s} \text { health_dir }{ }_{i t-1}+\beta_{9 s} \text { health_indir }{ }_{i t}+\beta_{10 s} \text { health_indir } r_{i t-1}\right) \\
& +\sum_{k=11}^{23}\left(\beta_{k} \text { socio }_{i}\right)+c_{2 i}+u_{i t}
\end{aligned}
$$

where $c_{1 i}$ account for unobserved heterogeneity in the participation decision and $c_{2 i}$ account for unobserved heterogeneity in the consumption decision

\section{Estimation and Results}

A double hurdle models for vegetable consumption is estimated using the Craggit procedure in STATA 10 (Burke, 2009). We account for the panel structure in the data by using the correlated random effects (CRE) following Mundlak (1978) and Chamberlain (1984). Hence, we specify a model for the distribution of unobserved heterogeneity $c_{1 i}$ in equation 7 and $c_{2 i}$ in equation 8 as a linear function of the time averages of the explanatory variables, $\bar{x}_{i}$ and $\bar{w}_{i}$. We assume that the remaining unobserved heterogeneity is normally distributed and independent of the $x$ 'es and the $w$ 's (the explanatory variables), (Note 12) hence $c_{1 i}=\xi_{1} \bar{x}_{i}+\gamma_{1 i}$ and $c_{2 i}=\xi_{2} \bar{w}_{i}+\gamma_{2 i},\left(\begin{array}{l}\gamma_{1 i} \\ \gamma_{2 i}\end{array}\right) \sim$ Normal $\left(\begin{array}{l}0, \sigma_{1}^{2} \\ 0, \sigma_{2}^{2}\end{array}\right)$. Any time varying variable, including time trends, should be part of 
$\bar{x}_{i}$ and $\bar{w}_{i}$, since we have an unbalanced panel (Wooldridge, 2010). Since the CRE estimator is a simple transformation of the time constant unobservable heterogeneity into a function of observable time-constants, which is then substituted into the primary equations in the model, this has no effect on the likelihood shown in (6).

A Likelihood ratio test is performed to test the Tobit model against the Double Hurdle model (Lin \& Schmidt, 1984 ) which reveals a probability value of 0.0000 , hence the hypotheses that the decision to buy organics consist of just one decision is rejected. An LR-test of the exclusion of prices in the first step reveals a probability value of 0.1510 implying that we cannot reject the hypotheses that prices can be excluded in the first step of the model. Another LR-test reveals that total expenditure has to be included in the first step. It seems reasonable to include total expenditure in the first step since the larger the expenditure on fruits and vegetables the larger is the probability that an organic purchase is made.

We therefore re-estimate the model excluding price in the first step. The variables in the first hurdle $\left(x_{i}\right)$ and the second hurdle $\left(w_{i}\right)$ therefore now differ. The parameters from the estimation are shown in appendix A. The calculated probabilities of observing a purchase, as well as conditional and unconditional expected quantity shares are shown in table 5 below. These are mainly used as a check of the model fit. The estimated probability of making an organic purchase in a month $P[y>0]$ compare well with the calculated purchase frequencies from table 4 showing that the model does predict purchase frequencies rather precisely. Despite a smaller overvaluation of the quantity share for the convinced, the estimated unconditional quantity shares $E(y)$ are likewise equivalent to the observed organic quantity share from table 4 .

Table 5. Probability of observing a purchase as well as conditional and unconditional expectations

\begin{tabular}{llllllllllllllll}
\hline & \multicolumn{3}{l}{ Convinced } & \multicolumn{3}{l}{$\begin{array}{l}\text { Positive and food } \\
\text { involved }\end{array}$} & \multicolumn{2}{l}{$\begin{array}{l}\text { Positive and } \\
\text { convenient }\end{array}$} & \multicolumn{3}{c}{ Product focussed } & Indifferent & & \multicolumn{2}{c}{ Sceptics } \\
\hline & Mean & Std.err & Mean & Std.err & Mean & Std.err & Mean & Std.err & Mean & Std.err & Mean & Std.err \\
$\mathrm{P}[\mathrm{y}>0]$ & 0.429 & 0.1794 & 0.2564 & 0.1281 & 0.2616 & 0.1254 & 0.1200 & 0.0839 & 0.0889 & 0.0658 & 0.0692 & 0.0475 \\
$\mathrm{E}(\mathrm{y} \mid \mathrm{y}>0)$ & 0.414 & 0.1376 & 0.3180 & 0.1253 & 0.3516 & 0.1200 & 0.2703 & 0.1532 & 0.3137 & 0.1898 & 0.2413 & 0.1872 \\
$\mathrm{E}(\mathrm{y})$ & 0.178 & 0.0975 & 0.0785 & 0.0453 & 0.0881 & 0.0459 & 0.0300 & 0.0318 & 0.0235 & 0.0186 & 0.0149 & 0.0128 \\
\hline
\end{tabular}

To evaluate the effect of prices and information we calculate the partial effects. These can be calculated on three levels; the partial effects on the probability of making an organic purchase, the partial effects on conditional volume shares i.e. the effect on consumers who are already purchasing organics and finally the partial effects on unconditional volume shares i.e. the effect on observed organic volume shares. Table 6 below shows the partial effects on the probability of making an organic purchase; hence it describes how we can get consumers to make an organic purchase. For comparative reasons we have calculated the Partial Effect on the Average (PEA). Average Partial Effects (APE) are shown in appendix C and the equations used to calculate the partial effects are shown in appendix B. The standard errors are calculated using the delta method and the calculated probability values are shown in parentheses. Bold indicate significance at the 5 per cent level.

Concerning the partial effect of information the largest effects are from direct current negative information about pesticides in conventional vegetables (table 6), whereas no lagged effects are found. As we expected, relatively strong reactions are found among the three positive segments with lowest reaction found among the positive and convenient. This makes sense as this is the segment with the lowest food involvement amongst the positive segments and they are also generally less concerned about pesticides and artificial additives in their food, and slightly less convinced that organic products in general contain fewer pesticides and medicine residues (see table 2). Among the "negative" segments, the product focussed stand out as 59 per cent of them perceive that there are fewer pesticides and medicine residues in organic products versus only 40 and 41 per cent of the indifferent and the sceptics. The fact that the product focussed has a rather strong reaction towards information about pesticides in conventional vegetables therefore confirms the theory that households react stronger to information which confirms their initial beliefs.

Even the indifferent and at the 10 per cent level also the sceptics increase the probability of an organic purchase when they learn directly that there are pesticides in conventional vegetables, but they do not respond to indirect information about pesticides. We therefore find that all households care enough about their own health to react to direct negative information, and that the segments who initially believed in a difference in pesticide levels in organic and conventional foods also react to indirect negative information, but that the effect of indirect 
information is far smaller than the effect of direct information. As presented in table 2, the initial perception of positive health effects of organic products also varies a great deal among the segments, and especially between the three positive and the three negative segments. The positive segments are more likely to agree with the statement that organic products contain less pesticide and medicine residues than conventional products. This indicates that the 'fluffy' concept of 'organic is healthier' is not as easily conveyed as the physical measurements of pesticides and medicine residues. In Denmark organic products are generally talked about as being healthier, but the scientific evidence is lacking, while it is scientifically proven that organic vegetables contain fewer pesticides residues than conventional products whereas the negative health effects of the pesticides is still debated.

As expected only the most positive segments have a positive reaction towards information that connect health and organic consumption, which is due to the larger health orientation amongst those segments. Their initial positive attitude towards organic produce might also lower the information processing costs amongst these households. Furthermore, across all segments a significant negative reaction to indirect health information is observed. Health effects from consumption of organic vegetables are a matter of personal conviction rather than a scientific fact, and the effect of the opinion of others therefore depends strongly on whether one in generally agrees with these others, or not. If the papers you often read claim that organic is healthier you will think that it probably is, but on the other hand if the papers you do certainly NOT read claim that it is healthier it might actually reduce your own trust in positive health effects. The positive effect of expenditure on vegetables on the probability of making an organic purchase for the sceptics might be explained by that their organic purchases mainly are coincidental and more purchases in total increase the simple probability that one of the purchases in a given month are organic.

Table 6. Partial effects of information on the probability of observing a purchase

\begin{tabular}{|c|c|c|c|c|c|c|}
\hline \multicolumn{7}{|c|}{$\partial P[y>0] / \partial x$ (probability values in parentheses). Bold indicates significant at $5 \%$ level } \\
\hline & Convinced & Positive and food inv. & Positive and conv. & Product focussed & Indifferent & Sceptics \\
\hline \multirow[t]{2}{*}{ Pest_dir } & 0.0735 & 0.0791 & 0.0509 & 0.0588 & 0.0708 & 0.0416 \\
\hline & $(0.0000)$ & $(0.0000)$ & $(0.0034)$ & $(0.0000)$ & $(0.0112)$ & $(0.0894)$ \\
\hline \multirow[t]{2}{*}{ Pest_indir } & 0.0157 & 0.0148 & 0.0094 & 0.0068 & 0.0100 & 0.0057 \\
\hline & $(0.0000)$ & $(0.0000)$ & $(0.0141)$ & $(0.0368)$ & $(0.1354)$ & $(0.3003)$ \\
\hline \multirow[t]{2}{*}{ Pest_dir -1} & 0.0239 & -0.0394 & -0.0073 & 0.0100 & -0.0048 & -0.0411 \\
\hline & $(0.4099)$ & $(0.0937)$ & $(0.8090)$ & $(0.6888)$ & $(0.9297)$ & $(0.3730)$ \\
\hline \multirow[t]{2}{*}{ Pest_indir ${ }_{-1}$} & -0.0041 & 0.0065 & 0.0003 & -0.0041 & -0.0014 & 0.0029 \\
\hline & $(0.1868)$ & $(0.0102)$ & $(0.9233)$ & $(0.1404)$ & $(0.8104)$ & $(0.5527)$ \\
\hline \multirow[t]{2}{*}{ Health_dir } & 0.0260 & 0.0182 & -0.0102 & 0.0098 & 0.0123 & 0.0152 \\
\hline & $(0.0036)$ & $(0.0163)$ & $(0.3096)$ & $(0.2508)$ & $(0.4751)$ & $(0.2989)$ \\
\hline \multirow[t]{2}{*}{ Health_indir } & -0.0101 & -0.0055 & -0.0035 & -0.0048 & -0.0075 & -0.0050 \\
\hline & $(0.0000)$ & $(0.0000)$ & $(0.0388)$ & $(0.0012)$ & $(0.0145)$ & $(0.0458)$ \\
\hline \multirow[t]{2}{*}{ Health_dir ${ }_{-1}$} & -0.0074 & -0.0107 & -0.0076 & -0.0050 & -0.0260 & -0.0209 \\
\hline & $(0.3889)$ & $(0.2639)$ & $(0.4252)$ & $(0.7717)$ & $(0.1301)$ & $(0.1500)$ \\
\hline \multirow[t]{2}{*}{ Health_indir ${ }_{-1}$} & 0.0009 & 0.0010 & 0.0008 & -0.0007 & -0.0025 & -0.0009 \\
\hline & $(0.4863)$ & $(0.3710)$ & $(0.5623)$ & $(0.5638)$ & $(0.3088)$ & $(0.6500)$ \\
\hline \multirow[t]{2}{*}{ Monthly exp } & 0.0238 & 0.0126 & 0.0073 & 0.0073 & 0.0067 & 0.0138 \\
\hline & $(0.0000)$ & $(0.0000)$ & $(0.0246)$ & $(0.0102)$ & $(0.2296)$ & $(0.0037)$ \\
\hline
\end{tabular}

The partial effects on conditional volume shares (the organic volume shares for those consumers that have decided to make an organic purchase in a given month) are given in table 7. One striking result from this table is the large positive reaction from the three negative segments to indirect information that link health and consumption of organic vegetables. Due to their lower health orientation and lack of confidence in the health attributes from organic they were expected to have a rather small reaction. The explanation for this might be that we consider households that have decided to make an organic purchase for some reason (they have decided to be market participants) (Note 13) and they will react differently than the corresponding group of non-participants. This might support the hypothesis by Gottschalk and Leistner (2012) that repeated purchases might follow a 
positive experience from a first time purchase. Comparing the reaction within the positive segments the size of the reaction is larger for the positive and food involved and the positive and convenient than for the convinced. This might be due to diminishing marginal effect of information. The effect is larger for the positive and food involved than the positive and convenient as anticipated due to a larger degree of health orientation.

Only the two most positive segments will increase their share of organic vegetables if they increase their total expenditure on fruits and vegetables. Reactions to price follow the expected pattern with largest price sensitivity from the product focussed and the sceptics. The indifferent seem not to react on prices, which are explainable due to their general ignorant attitude towards food. The positive and food involved and the positive and convenient exhibit, as expected, larger sensitivity towards prices than the convinced.

Table 7. Partial effect on the conditional volume shares

\begin{tabular}{|c|c|c|c|c|c|c|}
\hline \multicolumn{7}{|c|}{$\partial E[y \mid y>0] / \partial x$ (probability values in parenthesis). Bold indicates significant at $5 \%$ level } \\
\hline & Convinced & Positive and food inv & Positive and conv. & Product focussed & Indifferent & Sceptics \\
\hline \multirow[t]{2}{*}{ Pest_dir } & 0.0190 & 0.0089 & -0.0266 & 0.0249 & -0.0646 & -0.0075 \\
\hline & $(0.0453)$ & $(0.5040)$ & $(0.0674)$ & $(0.4793)$ & $(0.0177)$ & $(0.8297)$ \\
\hline \multirow[t]{2}{*}{ Pest_indir } & 0.0009 & -0.0019 & -0.0036 & -0.0239 & 0.0020 & -0.0060 \\
\hline & $(0.6897)$ & $(0.5390)$ & $(0.2435)$ & $(0.0197)$ & $(0.7083)$ & $(0.4000)$ \\
\hline \multirow[t]{2}{*}{ Pest_dir ${ }_{-1}$} & 0.0056 & -0.0382 & -0.0287 & -0.0256 & -0.1704 & -0.0784 \\
\hline & $(0.7407)$ & $(0.1214)$ & $(0.2477)$ & $(0.6652)$ & $(0.0009)$ & $(0.2711)$ \\
\hline \multirow[t]{2}{*}{ Pest_indir -1} & 0.0011 & 0.0043 & -0.0020 & 0.0056 & 0.0091 & 0.0011 \\
\hline & $(0.5521)$ & $(0.1021)$ & $(0.4491)$ & $(0.4060)$ & $(0.0647)$ & $(0.8785)$ \\
\hline \multirow[t]{2}{*}{ Health_dir } & 0.0085 & 0.0060 & 0.0024 & -0.0220 & -0.0311 & 0.0151 \\
\hline & $(0.1294)$ & $(0.4434)$ & $(0.7629)$ & $(0.2923)$ & $(0.0437)$ & $(0.5168)$ \\
\hline \multirow[t]{2}{*}{ Health_indir } & 0.0032 & 0.0076 & 0.0053 & 0.0209 & 0.0121 & 0.0106 \\
\hline & $(0.0006)$ & $(0.0000)$ & $(0.0001)$ & $(0.0000)$ & $(0.0001)$ & $(0.0060)$ \\
\hline \multirow[t]{2}{*}{ Health_dir ${ }_{-1}$} & 0.0090 & 0.0129 & 0.0067 & -0.0776 & 0.0321 & -0.0551 \\
\hline & $(0.0834)$ & $(0.0977)$ & $(0.3790)$ & $(0.0032)$ & $(0.0226)$ & $(0.0547)$ \\
\hline \multirow[t]{2}{*}{ Health_indir ${ }_{-1}$} & -0.0003 & -0.0008 & -0.0013 & -0.0038 & 0.0018 & -0.0002 \\
\hline & $(0.6819)$ & $(0.4393)$ & $(0.2495)$ & $(0.2288)$ & $(0.3792)$ & $(0.9321)$ \\
\hline \multirow[t]{2}{*}{ Relative price } & -0.3030 & -0.4620 & -0.3858 & -1.1811 & -0.2928 & -0.7936 \\
\hline & $(0.000)$ & $(0.0000)$ & $(0.0000)$ & $(0.0008)$ & $(0.0762)$ & $(0.0031)$ \\
\hline \multirow[t]{2}{*}{ Monthly exp } & 0.0147 & 0.0090 & 0.0029 & -0.0153 & -0.0013 & -0.0012 \\
\hline & $(0.0000)$ & $(0.0008)$ & $(0.2617)$ & $(0.0551)$ & $(0.7803)$ & $(0.8567)$ \\
\hline
\end{tabular}

In table 8 below we consider the partial effects on the unconditional market share, hence these effects of exogenous information and changing prices are the effects we will see on observed organic market shares. Generally we see the same pattern in prices as we observed on conditional volume shares with the largest reaction to the relative price between organic and conventional vegetables from the negative segments and the smallest reaction from the convinced and the indifferent. All of the positive segments increase their volume share of organic vegetables if they increase their expenditure on fruits and vegetables, and so do the sceptics, again probably because the organic budget share of the sceptics is mainly a result of random purchases. The effect of information is mainly limited to the positive segments which support the hypothesis that information which is in accordance with initial attitudes and believes lower processing cost and increase the reaction. The one exception is the product focussed segment which has a positive and rather strong reaction to information about pesticides in conventional vegetables which again might be attributed to their concern about the adverse effects of conventional agricultural production. Only the two most positive segments and the product focussed react to information that link health and the consumption of organic vegetables. 
Table 8. Partial effect on the unconditional volume shares

\begin{tabular}{lllllll}
\hline$\partial E[y] / \partial x$ & (probability values in parenthesis). Bold indicates significant at 5\% level & & & \\
& Convinced & Positive and food inv. & Positive and conv. & Product focussed & Indifferent & Sceptics \\
\hline Pest_dir & 0.0276 & 0.0270 & 0.0099 & 0.0243 & 0.0074 & 0.0114 \\
& $(0.0000)$ & $(0.000)$ & $(0.0421)$ & $(0.0005)$ & $(0.3857)$ & $(0.1884)$ \\
Pest_indir & 0.0052 & 0.0042 & 0.0021 & -0.0034 & 0.0036 & 0.0004 \\
& $(0.0000)$ & $(0.0000)$ & $(0.0451)$ & $(0.0788)$ & $(0.0632)$ & $(0.8259)$ \\
Pest_dir-1 & 0.0088 & -0.0213 & -0.0089 & -0.0028 & -0.0409 & -0.0311 \\
& $(0.2702)$ & $(0.0039)$ & $(0.3121)$ & $(0.8154)$ & $(0.0127)$ & $(0.0660)$ \\
Pest_indir-1 & -0.0010 & 0.0031 & -0.0004 & 0.0000 & 0.0017 & 0.0012 \\
& $(0.2269)$ & $(0.0001)$ & $(0.7050)$ & $(0.9952)$ & $(0.3285)$ & $(0.5041)$ \\
Health_dir & 0.0102 & 0.0071 & -0.0027 & -0.0020 & -0.0033 & 0.0083 \\
& $(0.0000)$ & $(0.0025)$ & $(0.3633)$ & $(0.6304)$ & $(0.5203)$ & $(0.1281)$ \\
Health_indir & -0.0025 & 0.0000 & 0.0001 & 0.0033 & 0.0004 & 0.0009 \\
& $(0.0000)$ & $(0.9982)$ & $(0.8125)$ & $(0.0003)$ & $(0.6404)$ & $(0.3300)$ \\
Health_dir-1 & -0.0003 & -0.0004 & -0.0009 & -0.0195 & -0.0008 & -0.0193 \\
& $(0.9101)$ & $(0.8609)$ & $(0.7604)$ & $(0.0001)$ & $(0.8795)$ & $(0.0016)$ \\
Health_indir-1 & 0.0002 & 0.0001 & 0.0000 & -0.0011 & -0.0004 & -0.0003 \\
& $(0.5623)$ & $(0.7486)$ & $(0.9282)$ & $(0.0749)$ & $(0.5980)$ & $(0.6239)$ \\
Relative price & -0.0511 & -0.0779 & -0.0650 & -0.1990 & -0.0494 & -0.1337 \\
& $(0.0000)$ & $(0.0000)$ & $(0.0000)$ & $(0.0008)$ & $(0.0762)$ & $(0.0031)$ \\
Monthly exp & 0.0109 & 0.0060 & 0.0030 & 0.0012 & 0.0018 & 0.0041 \\
& $(0.0000)$ & $(0.0000)$ & $(0.0017)$ & $(0.4297)$ & $(0.2624)$ & $(0.0147)$ \\
\hline
\end{tabular}

\section{Discussion and Conclusion}

As anticipated we found positive effects of information on the probability of purchasing organic and on organic volume shares. Furthermore the hypothesis of a larger effect of information for households where the information is in accordance with initial knowledge and attitudes are supported. We find a larger reaction from the positive organic segments who have initial positive attitudes towards organics, who have larger health orientation and who worry more about pesticides and additives in their food. These segments furthermore perceive organic varieties to contain smaller amounts of pesticides and additives. Generally negative information, i.e. information about incidents of pesticides in conventional vegetables is found to have a larger effect on unconditional organic volumes shares than positive information i.e. information that link health and the consumption of organic vegetables. This is a general result from the literature (Verbeke, 2005).

Basically we find that the market share for organic vegetables is influenced by both information about pesticides in conventional vegetables and information that link health and the consumption of organic vegetables but mainly for consumers that have initial attitudes in correspondence with the message i.e. only the positive segments. The effect of information about pesticides in conventional vegetables on the product focussed is here an exception, but as consumers in this segment generally are concerned with the adverse effects of conventional production this also supports the hypothesis. This also suggests that marketing which focuses on the absence of pesticides in organic vegetables should have a large effect on this segment.

However from a marketing perspective the most interesting results from this study is the diverging effect of information on each step of the purchasing procedure. Negative information i.e. information that focus on the incidence of pesticides in conventional vegetables, is found to increase the probability of an organic purchase within all segments. Hence "new" organic consumers can be formed by providing information about the adverse effect of conventional agricultural production or by focussing on the absence of adverse effects in organic production. If the experience of a first time purchase is positive these new consumers may be converted into regular organic purchasers. The large and positive effect of information that link health and the consumption of organic vegetables on conditional market shares then indicate that both these "new" organic consumers as well as the "old" organic consumers will increase their volume share of organic vegetables if they are exposed to information that focus on the positive health effects of consuming organic.

Basically the findings from this study underline the importance of targeting information to be in accordance with the initial attitudes of the target group and to provide different types of information to consumers at different stages of the purchasing process. Also, as we find large price elasticities for organic vegetables for the less 
dedicated organic consumers, prices might be a barrier toward increasing the purchases of organic vegetables even though these consumers have been converted into organic purchases. Hence special offers or other ways of lowering the prices are likely to get those consumers to increase their consumption of organic vegetables to a larger extent than it is the case for the dedicated consumers.

\section{References}

Adhikari, M., Paudel, L., Houston, J. F., Paudel, K. P., \& Bukenya, J. (2006). Impacts of Cholesterol Information on Meat Demand: An Application of Updated Cholesterol Index. Journal of food distribution research, 37, 61-68.

Andersen, L. M. (2008). Information Provision to Consumers as an Instrument of Environmental Regulation. (PhD thesis). University of Copenhagen, Phd-series no. 130.

Andersen, L. M. (2009). Documentation of CONCEPTS questionnaire. Retrieved from http://orgprints.org/15741/1/15741.pdf (verified November 2012).

Atkinson, A. B., Gomulka, J., \& Stern, N. H. (2008). Household expenditure on tobacco 1970-1980: Evidence from the family expenditure survey. ESRC Programme on taxation incentives and the distribution of income, London school of economics, Discussion paper no. 60. 2008.

Becker, G. (1965). A theory of the allocation of time. The Economic Journal, 75, 493-517. http://dx.doi.org/10.2307/2228949

Burke, W. J. (2009). Fitting and interpreting Cragg's tobit alternative using Stata. The Stata Journal, 9, 584-592.

Chamberlain, G. (1984). Panel data. In Z. Griliches \& M. Intriligator (Eds), Handbook of Econometrics (Vol. 3, pp. 1465-1514). New York.

Darby, M. R., \& Karni, E. (1973). Free competition and the optimal amount of fraud. The journal of law and economics, 16, 67-88. http://dx.doi.org/10.1086/466756

Deaton, A. S., \& Irish, M. (1984). Statistical models for zero expenditure in household budgets. Journal of Public Economics, 23, 59-80. http://dx.doi.org/10.1016/0047-2727(84)90067-7

Garcia, J., \& Labeaga, J. M. (1996). Alternative Approaches to Modeling Zero Expenditure: An Application to Spanish Demand for Tobacco. Oxford Bulletin of Economics and Statistics, 58, 489-504. http://dx.doi.org/10.1111/j.1468-0084.1996.mp58003004.x

Gottschalk, I., \& Leistner, T. (2012). Consumer reaction to the availability of organic food in discount supermarkets. International Journal of Consumer studies. http://dx.doi.org/10.1111/j.1470-6431.2012.01101.x

Hamm, U., \& Michelsen, J. (1996). Organic Agriculture in a Market Economy. Perspectives from Germany and Denmark. In Østergaard, T. (Ed.), Fundamentals of Organic Agriculture - Proceedings from the $11^{\text {th }}$ IFOAM International Scientific Conference, August 11-15, Copenhagen.

Heiman, A., \& Lowengart, O. (2008). The effect of information about health hazards on demand for frequently purchased commodities. International Journal of Research in Marketing, 25, 310-318. http://dx.doi.org/10.1016/j.ijresmar.2008.07.002

Holm, L., \& Kildevang, H. (1996). Consumers' Views on Food Quality. A Qualitative Interview Study. Appetite, 27, 1-14. http://dx.doi.org/10.1006/appe.1996.0029

Hughner, R. S., McDonagh, P., Prothero, Shultz, J. S., \& Stanton, J. (2007). Who are organic food consumers? a compilation and review of why people purchase organic food. Journal of Consumer Behavior, 6, 94-110. http://dx.doi.org/10.1002/cb.210

IFOAM. (2005). IFOAM Norms for Organic Production and Processing. Available at http://shop.ifoam.org/bookstore/product_info.php?cPath=64_24\&products_id=74 (verified November 2012)

Jolly, D. A., Schutz, G. H., Diaz-Knauf, K. V., \& Johal, J. (1989). Organic foods: Consumer attitudes and use. Food Technology, 43, 60-66.

Jones, A. M. (1989). A double hurdle model of cigarette consumption. Journal of applied Econometrics, 4, 23-29. http://dx.doi.org/10.1002/jae.3950040103

Jones, A. M. (1992). A Note on Computation of the Double - Hurdle Model With Dependence With An Application to Tobacco Expenditure. Bulletin of Economic Research, 44, 67-74. 
http://dx.doi.org/10.1111/j.1467-8586.1992.tb00507.x

Kalaitzandonakes, N., Marks, L. A., \& Vickner, S. S. (2004). Media coverage of biotech foods and influence on consumer choice. American Journal of Agricultural Economics, 86, 1238-1246. http://dx.doi.org/10.1002/jae.3950040103

Lin, T., \& Schmidt, P. (1984). A test of the Tobit specification against an alternative suggested by Cragg. Review of economics and Statistics, 66, 174-177. http://dx.doi.org/10.2307/1924712

Lund, T. B., Andersen, L. M., \& Jensen, K. O. (2012). The emergence of diverse organic consumers: Who are they and how do they shape demand? FOI Working Paper No. 2012/5.

Lusk, J. L. (2004). The effect of proposition 2 on the demand for eggs in California. Journal of Agricultural \& Food Industrial Organization, 8, 1-18.

McCluskey, J. J., \& Swinnen, J. F. M. (2004). Political economy of the media and consumer perceptions of biotechnology. American Journal of Agricultural Economics, 86, 1230-1237. http://dx.doi.org/10.1111/j.0002-9092.2004.00670.x

McCluskey, J. J., \& Swinnen, J. F. M. (2007). Rational Ignorance and Negative News in the Information Market. LICOS Discussion Paper No. 191/2007. http://dx.doi.org/10.2139/ssrn.1106113

McGuirk, A., Driscoll, P., Alwang, J., \& Huang, H. (1995). Testing and Change in the Demand for Meat. Journal of Agricultural and Resource Economics, 20, 1-21.

Midmore, P., Naspatti, S., Sherwood, A. M., Vairo, D., Wier, M., \& Zanoli, R. (2005). Consumer attitudes to quality and safety of organic and low input foods: a review. Available online at http://www.qlif.org/research/sub1/QLIF_Review_Reanalysis_\%200509.pdf (verified November 2012)

Mundlak, Y. (1978). On the pooling of time series and cross-section data. Econometrica, 46, 69-85. http://dx.doi.org/10.2307/1913646

Nelson, P. (1970). Information and consumer behavior. Journal of Political Economy, 78, 311-329. http://dx.doi.org/10.1086/259630

Nie, C., \& Zepeda, L. (2011). Lifestyle segmentation of US food shoppers to examine organic and local food consumption. Appetite, 57, 28-37. http://dx.doi.org/10.1016/j.appet.2011.03.012

O’Donovan, P., \& McCarthy, M. (2002). Irish consumer preference for organic meat. British Food Journal, 104, 353-370. http://dx.doi.org/10.1108/00070700210425778

OECD. (2012). What are equivalence scales? Available at http://www.oecd.org/dataoecd/61/52/35411111.pdf (verified November 2012).

Økologisk Landsforening. (2012). Organic Market memomrandum. Juni 2012 (In Danish) http://www.okologi.dk/media/2009035/markedsnotat\%202012.pdf(Verified November 2012).

Padel, S., Schaack, D., \& Willer, H. (2009). Development of the Organic Market in Europe. In Willer, H. and K. Lukas (Eds.), The world of organic agriculture. statistics and emerging trends 2009 (pp. 155-164). Bonn: IFOAM.

Pearson, D., Henryks, J., \& Jones, H. (2011). Organic food: What we know (and do not know) about consumers. Renewable Agriculture and Food Systems, 26, 171-177. http://dx.doi.org/10.1017/S1742170510000499

Piggott, N. E., \& Marsh, T. L. (2004). Does food safety information impact US meat demand? American Journal of Agricultural Economics, 86, 154-174. http://dx.doi.org/10.1111/j.0092-5853.2004.00569.x

Pudney, S. (1989) Modelling Individual Choice: The Econometrics of Corners, Kinks and Holes. New York: Basil Blackwell.

Richter, T. (2008) Trends in the organic retailing sector in Europe 2007. In Willer, H. M. Yussefi-Menzler \& N. Sorensen (Eds.), The world of organic agriculture. statistics and emerging trends 2008 (pp. 140-142). Bonn: IFOAM.

Schmidt, T. M., \& Kaiser, H. M. (2003). Dietary cholesterol concerns and demand for eggs. In Chern, S. \& Rickertsen, K. (Eds.), Health Nutrition and Food Demand. Cambridge, MA: CABI Publishing. http://dx.doi.org/10.1079/9780851996479.0203

Smed, S. (2008). Empirical studies on Health, Information and Consumer Behaviour. (PhD thesis). University of Copenhagen, Phd series no. 128. 
Smed, S. (2012). Information and consumer perception of the organic attribute - the case of fresh organic fruit and vegetables. Agricultural Economics, 34 (s1), 33-48. DOI: 10.1111/j.1574-0862.2012.00618.x

Swinnen, J. F. M., McCluskey, J. J., \& Francken, N. (2005). Food safety, the media, and the information market. In D. Colman \& N. Vinck (Eds), Reshaping Agriculture's Contribution to Society (pp. 175-188). Oxford: Blackwell.

Tobin, J. (1958). Estimation of relationships for limited dependent variables. Econometrica, 26, 246-251. http://dx.doi.org/10.2307/1907382

Tonsor, G. T., \& Olynk, N. J. (2010). Impacts of Animal Well-Being and Welfare Media on Meat Demand. Journal of Agricultural Economics, 62, 59-72. http://dx.doi.org/10.1111/j.1477-9552.2010.00266.x

Tonsor, G. T., Mintert, J. R., \& Schroeder, T. C. (2010). U.S. Meat Demand: Household Dynamics and Media Information Impacts. Journal of Agricultural and Resource Economics, 35, 1-17.

Törnquist, L. (1936). The bank of Finland's consumption price index. Bank of Finland Monthly Bulletin, 10, 1-8.

Verbeke, W. (2005). Agriculture and the food industry in the information age. European review of agricultural economics, 32, 347-368. http://dx.doi.org/10.1093/eurrag/jbi017

Verbeke, W., \& Ward, R. W. (2001). A fresh meat almost ideal demand system incorporating negative TV press $\begin{array}{lllll}\text { and advertising impact. Agricultural } & \text { Economics, } & \text { 25, }\end{array}$ http://dx.doi.org/10.1111/j.1574-0862.2001.tb00215.x

Vindigni, G., Janssen, M. A., \& Jager, W. (2002). Organic food consumption: A multi-theoretical framework of consumer decision making. British Food Journal, 104, 624-642. http://dx.doi.org/10.1108/00070700210425949

Wooldridge, J. M. (2010). Correlated random effects model with unbalanced panels. Manuscript Version July, 2009. Michigan State University. http://econ.msu.edu/faculty/wooldridge/docs/cre1_r4.pdf (Verified November 2012).

\section{Notes}

Note 1. For a more throughout description of the data see the data section below.

Note 2. Food involvement is a complex variable referring to expressed attitudes and reported or observed practices regarding shopping and cooking (Lund et al., 2012). In the latent class analysis food involvement is defined by reactions to the questions: 'I am not very interested in food and cooking', 'Food is an important part of the joy of life for me' and 'As far as possible I make food from scratch and avoid readymade meals'.

Note 3. In the LCA analysis price sensitivity refers to the answers to the general statement: 'Price is more important for me than quality'.

Note 4. In the LCA analysis trust in organic production is measured by the questions: 'Organic foods are just a fashionable fad' and 'Organic is a sales gimmick'.

Note 5. Intrinsic qualities of organic foods refer to general assessments of these products including such aspects as appearance, freshness, taste and health benefits, while altruistic concerns refer to consideration of the consequences of product choices for the environment, animal welfare or climate change (Lund et al., 2012). In the LCA analysis intrinsic quality are measured by the questions: 'I think that organic products are healthier for me and my family than conventional products' and 'Generally, organic products are of a poorer quality', while altruistic concerns are measured by the question 'It is important to consider the consequences of one's shopping on the outside world'.

Note 6. For more information on GfK ConsumerTracking Scandinavia see http://www.gfk.dk/, Andersen (2008) or Smed (2008).

Note 7. Data has been selected so the minimum length of stay in the panel is 12 months; the maximum length is 72 months.

Note 8. For other examples of this types of indices see e.g. Piggott \& Marsh (2004), McGuirk et al. (1995), Schmidt \& Kaiser (2003), Verbeke \& Ward (2001), Tonsor \& Olynk (2010) and Tonsor et al. (2010).

Note 9 . A regular reader is here defined as a household that state that they read at least 3 out of 6 weekly editions of the particular newspaper.

Note 10. Introducing additional lags does not change the conclusions of the model and these additional lags are insignificant. 
Note 11. Several studies have relaxed the independent error term assumption using the rationale that an individual's decision about whether to purchase and his decision about how much to purchase may be linked, thus generating dependent errors (Garcia \& Labeaga, 1996). Studies that have compared the results from a model where independence in the errors is assumed, with the results from the same model where the assumption is relaxed, have found virtually identical coefficients and standard errors (Jones, 1992; Garcia \& Labeaga, 1996).

Note 12. The CRE adjustment and the inclusion of a large number of socio-demographic variables are assumed to a satisfactory degree to control for the unobserved heterogeneity in the dataset especially because the literature shows that there is a large degree of correlation between the included socio-demographic variables and the size of the budget share for organic foods (Hughner et al., 2007).

Note 13. This group is however rather small for the indifferent and the sceptics.

\section{Appendix A. Parameter Estimates}

Table A1. Parameter estimates

\begin{tabular}{|c|c|c|c|c|c|c|}
\hline & \multicolumn{3}{|c|}{$\begin{array}{l}\text { Participation equation } \\
\text { (first hurdle, probit) }\end{array}$} & \multicolumn{3}{|c|}{$\begin{array}{l}\text { Consumption equation } \\
\text { (second hurdle, tobit) }\end{array}$} \\
\hline & Coef. & Std. Err. & $\mathbf{P}>\mathbf{z}$ & Coef. & Std. Err. & $\mathbf{P}>\mathbf{z}$ \\
\hline Constant, (Convinced is base) & 0.0125 & 1.0418 & 0.9900 & 4.0070 & 0.9235 & 0.0000 \\
\hline Positive and food involved & -1.8333 & 1.1910 & 0.1240 & -0.4286 & 1.2584 & 0.7330 \\
\hline Positive and convenient & -2.1078 & 1.3138 & 0.1090 & -3.4916 & 1.1589 & 0.0030 \\
\hline Product focussed & -2.1171 & 1.2940 & 0.1020 & 7.6522 & 3.6106 & 0.0340 \\
\hline Indifferent & -2.8304 & 1.7725 & 0.1100 & -4.3792 & 2.3261 & 0.0600 \\
\hline Sceptics & -0.8903 & 2.4117 & 0.7120 & -0.9284 & 6.5347 & 0.8870 \\
\hline Trend_conv & -0.0095 & 0.0142 & 0.5040 & -0.0027 & 0.0123 & 0.8240 \\
\hline Trend_pos_food inv. & 0.0007 & 0.0120 & 0.9550 & 0.0099 & 0.0182 & 0.5890 \\
\hline Trend_pos_conv. & -0.0048 & 0.0158 & 0.7630 & -0.0106 & 0.0161 & 0.5120 \\
\hline Trend_prod_foc & 0.0085 & 0.0136 & 0.5310 & 0.0187 & 0.0601 & 0.7550 \\
\hline Trend_indiff & -0.0244 & 0.0264 & 0.3560 & -0.0518 & 0.0270 & 0.0550 \\
\hline Trend_sceptic & 0.0394 & 0.0236 & 0.0950 & 0.0779 & 0.0864 & 0.3670 \\
\hline Trend $^{\overline{2}}$ conv & 0.0005 & 0.0005 & 0.3650 & 0.0001 & 0.0004 & 0.8060 \\
\hline Trend $^{2}$ pos_food inv & 0.0000 & 0.0005 & 0.9200 & -0.0004 & 0.0006 & 0.5020 \\
\hline Trend $^{2}$ pos_conv & 0.0002 & 0.0006 & 0.7920 & 0.0004 & 0.0006 & 0.4860 \\
\hline Trend $^{2}$ prod_foc & -0.0004 & 0.0005 & 0.4300 & -0.0017 & 0.0019 & 0.3550 \\
\hline Trend $^{2}$ indiff & 0.0009 & 0.0010 & 0.3550 & 0.0015 & 0.0011 & 0.1780 \\
\hline Trend $^{2}$ _sceptic & -0.0015 & 0.0009 & 0.0980 & -0.0010 & 0.0021 & 0.6400 \\
\hline Relative price_conv & & & & -1.5641 & 0.3115 & 0.0000 \\
\hline Relative price_pos_food inv & & & & -2.3849 & 0.4736 & 0.0000 \\
\hline Relative price_pos_conv & & & & -1.9915 & 0.4425 & 0.0000 \\
\hline Relative price_prod_foc & & & & -6.0963 & 1.8108 & 0.0010 \\
\hline Relative price_indiff & & & & -1.5115 & 0.8516 & 0.0760 \\
\hline Relative price_sceptic & & & & -4.0963 & 1.3816 & 0.0030 \\
\hline Pest_dir_conv & 0.2919 & 0.0639 & 0.0000 & 0.0707 & 0.0488 & 0.1480 \\
\hline Pest_dir_pos_food inv & 0.3143 & 0.0518 & 0.0000 & 0.0331 & 0.0685 & 0.6290 \\
\hline Pest_dir_pos_conv & 0.2022 & 0.0688 & 0.0030 & -0.0990 & 0.0749 & 0.1860 \\
\hline Pest_dir_prod_foc & 0.2335 & 0.0561 & 0.0000 & 0.0929 & 0.1819 & 0.6090 \\
\hline Pest_dir_indiff & 0.2815 & 0.1108 & 0.0110 & -0.2407 & 0.1403 & 0.0860 \\
\hline Pest_dir_sceptic & 0.1655 & 0.0973 & 0.0890 & -0.0281 & 0.1811 & 0.8770 \\
\hline Pest_indir_conv & 0.0624 & 0.0142 & 0.0000 & 0.0034 & 0.0118 & 0.7730 \\
\hline Pest_indir_pos_food inv & 0.0587 & 0.0118 & 0.0000 & -0.0071 & 0.0160 & 0.6570 \\
\hline Pest_indir_pos_conv & 0.0374 & 0.0152 & 0.0140 & -0.0134 & 0.0159 & 0.4000 \\
\hline Pest_indir_prod_foc & 0.0271 & 0.0129 & 0.0370 & -0.0889 & 0.0527 & 0.0920 \\
\hline Pest_indir_indiff & 0.0396 & 0.0265 & 0.1350 & 0.0073 & 0.0270 & 0.7870 \\
\hline Pest_indir_sceptic & 0.0228 & 0.0220 & 0.3000 & -0.0225 & 0.0371 & 0.5430 \\
\hline Pest_dir-1_conv & 0.0948 & 0.1150 & 0.4100 & 0.0208 & 0.0870 & 0.8110 \\
\hline Pest_dir-1_pos_food inv & -0.1566 & 0.0934 & 0.0930 & -0.1422 & 0.1271 & 0.2630 \\
\hline Pest_dir-1_pos_conv & -0.0290 & 0.1198 & 0.8090 & -0.1069 & 0.1280 & 0.4040 \\
\hline Pest_dir-1_prod_foc & 0.0396 & 0.0989 & 0.6890 & -0.0952 & 0.3047 & 0.7550 \\
\hline Pest_dir-1_indiff & -0.0189 & 0.2143 & 0.9300 & -0.6350 & 0.2648 & 0.0160 \\
\hline Pest_dir -1_sseptic $_{\text {s }}$ & -0.1633 & 0.1833 & 0.3730 & -0.2921 & 0.3675 & 0.4270 \\
\hline
\end{tabular}




\begin{tabular}{|c|c|c|c|c|c|c|}
\hline & \multicolumn{3}{|c|}{$\begin{array}{l}\text { Participation equation } \\
\text { (first hurdle, probit) }\end{array}$} & \multicolumn{3}{|c|}{$\begin{array}{l}\text { Consumption equation } \\
\text { (second hurdle, tobit) }\end{array}$} \\
\hline & Coef. & Std. Err. & $\mathbf{P}>\mathbf{z}$ & Coef. & Std. Err. & $\mathbf{P}>\mathbf{z}$ \\
\hline Pest_indir-1_conv & -0.0164 & 0.0124 & 0.1870 & 0.0041 & 0.0096 & 0.6680 \\
\hline 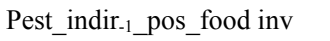 & 0.0260 & 0.0101 & 0.0100 & 0.0159 & 0.0135 & 0.2370 \\
\hline Pest_indir ${ }_{-1} \_$pos_conv & 0.0013 & 0.0130 & 0.9230 & -0.0074 & 0.0135 & 0.5850 \\
\hline Pest_indir -1_prod_foc & -0.0162 & 0.0110 & 0.1400 & 0.0209 & 0.0348 & 0.5480 \\
\hline Pest_indir ${ }_{-1}$ indiff & -0.0055 & 0.0230 & 0.8100 & 0.0340 & 0.0255 & 0.1820 \\
\hline Pest_indir ${ }_{-1} \_$sceptic & 0.0114 & 0.0191 & 0.5530 & 0.0041 & 0.0367 & 0.9120 \\
\hline Health_dir_conv & 0.1031 & 0.0354 & 0.0040 & 0.0317 & 0.0290 & 0.2730 \\
\hline Health_dir_pos_food inv & 0.0722 & 0.0300 & 0.0160 & 0.0223 & 0.0402 & 0.5800 \\
\hline Health_dir_pos_conv & -0.0406 & 0.0400 & 0.3090 & 0.0090 & 0.0415 & 0.8280 \\
\hline Health_dir_prod_foc & 0.0390 & 0.0340 & 0.2510 & -0.0822 & 0.1080 & 0.4470 \\
\hline Health_dir_indiff & 0.0489 & 0.0685 & 0.4750 & -0.1159 & 0.0795 & 0.1450 \\
\hline Health_dir_sceptic & 0.0604 & 0.0581 & 0.2990 & 0.0562 & 0.1199 & 0.6400 \\
\hline Health_indir_conv & -0.0403 & 0.0060 & 0.0000 & 0.0121 & 0.0049 & 0.0130 \\
\hline Health_indir_pos_food inv & -0.0220 & 0.0051 & 0.0000 & 0.0282 & 0.0071 & 0.0000 \\
\hline Health_indir_pos_conv & -0.0140 & 0.0068 & 0.0390 & 0.0198 & 0.0069 & 0.0040 \\
\hline Health_indir_prod_foc & -0.0189 & 0.0058 & 0.0010 & 0.0780 & 0.0255 & 0.0020 \\
\hline Health_indir_indiff & -0.0298 & 0.0121 & 0.0140 & 0.0451 & 0.0154 & 0.0030 \\
\hline Health_indir_sceptic & -0.0198 & 0.0099 & 0.0460 & 0.0396 & 0.0199 & 0.0470 \\
\hline Health_dir-1_conv & -0.0296 & 0.0343 & 0.3890 & 0.0335 & 0.0267 & 0.2110 \\
\hline Health_dir-1_pos_food inv & -0.0426 & 0.0290 & 0.1420 & 0.0480 & 0.0401 & 0.2310 \\
\hline Health_dir-1_pos_conv & -0.0304 & 0.0381 & 0.4250 & 0.0251 & 0.0396 & 0.5250 \\
\hline Health_dir -1_prod_foc & -0.0198 & 0.0322 & 0.5390 & -0.2893 & 0.1357 & 0.0330 \\
\hline Health_dir ${ }_{-1} \_$indiff & -0.1032 & 0.0681 & 0.1300 & 0.1197 & 0.0726 & 0.0990 \\
\hline Health_dir ${ }_{-1 \_}$sceptic & -0.0829 & 0.0575 & 0.1500 & -0.2052 & 0.1477 & 0.1650 \\
\hline Health_indir -1_conv & 0.0036 & 0.0051 & 0.4860 & -0.0012 & 0.0041 & 0.7670 \\
\hline Health_indir-1_pos_food inv & 0.0038 & 0.0043 & 0.3710 & -0.0032 & 0.0057 & 0.5760 \\
\hline Health_indir $-1 \_$pos_conv & 0.0033 & 0.0056 & 0.5620 & -0.0048 & 0.0057 & 0.4050 \\
\hline Health_indir ${ }_{-1}$ pprod_foc & -0.0028 & 0.0049 & 0.5640 & -0.0143 & 0.0164 & 0.3850 \\
\hline Health_indir-1_indiff & -0.0100 & 0.0098 & 0.3090 & 0.0067 & 0.0105 & 0.5250 \\
\hline Health_indir-1_sceptic & -0.0037 & 0.0081 & 0.6500 & -0.0009 & 0.0145 & 0.9510 \\
\hline Age & -0.0203 & 0.0054 & 0.0000 & -0.0074 & 0.0066 & 0.2600 \\
\hline $\mathrm{Age}^{2}$ & 0.0002 & 0.0000 & 0.0000 & 0.0000 & 0.0001 & 0.6530 \\
\hline Capital & 0.3007 & 0.0242 & 0.0000 & 0.0407 & 0.0290 & 0.1600 \\
\hline Town & 0.0018 & 0.0224 & 0.9360 & -0.0379 & 0.0306 & 0.2160 \\
\hline Children $_{0 \_6}$ _yrs & 0.0051 & 0.0415 & 0.9030 & -0.0761 & 0.0520 & 0.1430 \\
\hline 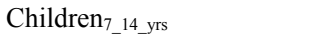 & 0.0124 & 0.0343 & 0.7170 & -0.0652 & 0.0468 & 0.1640 \\
\hline 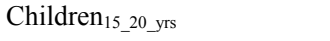 & -0.2070 & 0.0355 & 0.0000 & -0.1737 & 0.0530 & 0.0010 \\
\hline Voc. educ. & -0.0660 & 0.0277 & 0.0170 & -0.0554 & 0.0407 & 0.1740 \\
\hline Short educ. & 0.1215 & 0.0323 & 0.0000 & 0.1959 & 0.0437 & 0.0000 \\
\hline Medium/long educ. & 0.1572 & 0.0295 & 0.0000 & 0.2302 & 0.0418 & 0.0000 \\
\hline Monthly exp_conv & 0.0947 & 0.0117 & 0.0000 & 0.0547 & 0.0099 & 0.0000 \\
\hline Monthly exp_pos_food inv & 0.0499 & 0.0100 & 0.0000 & 0.0334 & 0.0137 & 0.0150 \\
\hline Monthly exp_pos_conv & 0.0291 & 0.0129 & 0.0240 & 0.0107 & 0.0132 & 0.4180 \\
\hline Monthly exp_prod_foc & 0.0291 & 0.0113 & 0.0100 & -0.0572 & 0.0413 & 0.1660 \\
\hline Monthly exp_indiff & 0.0266 & 0.0222 & 0.2290 & -0.0047 & 0.0232 & 0.8400 \\
\hline Monthly exp_sceptic & 0.0549 & 0.0188 & 0.0040 & -0.0045 & 0.0347 & 0.8960 \\
\hline
\end{tabular}

Monthly exp_sceptic

CRE parameters

\begin{tabular}{rrrrrrr}
\hline \multicolumn{3}{c}{$\begin{array}{c}\text { Participation equation } \\
\text { (first hurdle, probit) }\end{array}$} & & & \multicolumn{2}{c}{$\begin{array}{c}\text { Consumption equation } \\
\text { (second hurdle, tobit) }\end{array}$} \\
\hline Coef. & Std. Err. & $\mathbf{P}>\mathbf{z}$ & & Coef. & Std. Err. & $\mathbf{P}>\mathbf{z}$ \\
\hline-0.0228 & 0.1061 & 0.8300 & & 0.0768 & 0.1001 & 0.4430 \\
-0.0808 & 0.1017 & 0.4270 & & -0.0268 & 0.0927 & 0.7720 \\
-0.0106 & 0.1015 & 0.9170 & & 0.1109 & 0.0978 & 0.2570 \\
-0.0177 & 0.1059 & 0.8670 & & -0.2941 & 0.1446 & 0.0420 \\
0.0441 & 0.1129 & 0.6960 & & 0.0567 & 0.1166 & 0.6270 \\
-0.0081 & 0.1168 & 0.9450 & & -0.1382 & 0.1592 & 0.3850 \\
0.0004 & 0.0037 & 0.9170 & -0.0024 & 0.0036 & 0.4970 \\
& & & -39.2257 & 6.3307 & 0.0000 \\
\hline
\end{tabular}




\begin{tabular}{|c|c|c|c|c|c|c|}
\hline & \multicolumn{3}{|c|}{$\begin{array}{c}\text { Participation equation } \\
\text { (first hurdle, probit) }\end{array}$} & \multicolumn{3}{|c|}{$\begin{array}{l}\text { Consumption equation } \\
\text { (second hurdle, tobit) }\end{array}$} \\
\hline & Coef. & Std. Err. & $\mathbf{P}>\mathbf{Z}$ & Coef. & Std. Err. & $\mathbf{P}>\mathbf{Z}$ \\
\hline Relative price_pos_food inv & & & & -22.3521 & 7.0697 & 0.0020 \\
\hline Relative price_pos_conv & & & & -20.2244 & 4.1775 & 0.0000 \\
\hline Relative price_prod_foc & & & & -8.6672 & 10.5265 & 0.4100 \\
\hline Relative price_indiff & & & & -0.1948 & 8.0182 & 0.9810 \\
\hline Relative price_sceptic & & & & 39.2998 & 16.8736 & 0.0200 \\
\hline Pest_indir_conv & -0.2509 & 0.1265 & 0.0470 & 0.5914 & 0.1643 & 0.0000 \\
\hline Pest_indir_pos_food inv & 0.0553 & 0.1359 & 0.6840 & 0.5239 & 0.2014 & 0.0090 \\
\hline Pest_indir_pos_conv & 0.3095 & 0.1664 & 0.0630 & 0.5578 & 0.2045 & 0.0060 \\
\hline Pest_indir_prod_foc & -0.0182 & 0.1379 & 0.8950 & -0.3601 & 0.4176 & 0.3890 \\
\hline Pest_indir_indiff & -0.2776 & 0.2927 & 0.3430 & 0.0763 & 0.2956 & 0.7960 \\
\hline Pest_indir_sceptic & -0.1013 & 0.2872 & 0.7240 & -1.0906 & 0.6435 & 0.0900 \\
\hline Health_indir_conv & -0.3703 & 0.0869 & 0.0000 & -0.4761 & 0.1006 & 0.0000 \\
\hline Health_indir_pos_food inv & -0.1518 & 0.0774 & 0.0500 & -0.3209 & 0.1213 & 0.0080 \\
\hline Health_indir_pos_conv & -0.2587 & 0.0945 & 0.0060 & -0.0502 & 0.0871 & 0.5650 \\
\hline Health_indir_prod_foc & -0.2231 & 0.0854 & 0.0090 & -0.8288 & 0.3136 & 0.0080 \\
\hline Health_indir_indiff & -0.1124 & 0.1558 & 0.4710 & 0.2768 & 0.2212 & 0.2110 \\
\hline Health_indir_sceptic & -0.4684 & 0.2092 & 0.0250 & 0.1462 & 0.6059 & 0.8090 \\
\hline \multirow[t]{2}{*}{ Monthly exp. } & 0.4461 & 0.0169 & 0.0000 & -0.2468 & 0.0232 & 0.0000 \\
\hline & \multicolumn{6}{|c|}{ Sigma } \\
\hline Trend_conv & -0.0016 & 0.0022 & 0.4840 & & & \\
\hline Trend_pos_food inv & 0.0000 & 0.0029 & 0.9860 & & & \\
\hline Trend_pos_conv & 0.0006 & 0.0032 & 0.8440 & & & \\
\hline Trend_prod_foc & 0.0061 & 0.0081 & 0.4560 & & & \\
\hline Trend_indiff & 0.0029 & 0.0048 & 0.5360 & & & \\
\hline Trend_sceptic & -0.0120 & 0.0084 & 0.1540 & & & \\
\hline Positive and food involved & 0.0221 & 0.0562 & 0.6940 & & & \\
\hline Positive and convenient & -0.0485 & 0.0552 & 0.3790 & & & \\
\hline Product focussed & 0.1222 & 0.1220 & 0.3160 & & & \\
\hline Indifferent & -0.1735 & 0.0742 & 0.0190 & & & \\
\hline Sceptics & 0.1187 & 0.1496 & 0.4270 & & & \\
\hline Constant, Convinced is base & 0.4670 & 0.0346 & 0.0000 & & & \\
\hline
\end{tabular}

\section{Appendix B. Calculating Marginal Effects}

The probability of being a market participant is the probability of passing the first hurdle, which is modeled by a probit model. It can therefore be calculated as: $\quad P\left(y_{i t 1}^{*}>0 \mid w_{i t}\right)=\Phi(w \alpha)$ and the partial effect is calculated as:

$$
\frac{\partial P\left(y_{i t 1}^{*}>0 \mid w_{i t}\right)}{\partial x_{k}}=\alpha_{k} \varphi(w \alpha)
$$

for a continuous variable and

$$
\frac{\Delta P\left(y_{i t 1}^{*}>0 \mid w_{i t}\right)}{\Delta x_{k}}=\Phi\left(w \alpha^{1}\right)-\Phi\left(w \alpha^{0}\right)
$$

for a discrete variable.

Where $w \alpha^{1}=w_{1} \alpha_{1}+\ldots w_{k-1} \alpha_{k-1}+1 \cdot \alpha_{k}$ and $w \alpha^{0}=w_{1} \alpha_{1}+\ldots w_{k-1} \alpha_{k-1}+0 \cdot \alpha_{k}$

This number is interesting since it gives information about which variables have an influence on being a market participant.

The expected value of $y_{i}$ given that the consumer purchases organic (i.e. the consumer has passed both the first and the second hurdle and therefore we observe a positive purchase) is calculated as:

$E\left(y_{i t} \mid y_{i t}>0, x_{i t}\right)=x \beta+\sigma \cdot \lambda\left(\frac{x \beta}{\sigma}\right)$ where $\lambda(c)=\frac{\varphi(c)}{\Phi(c)}$ is the inverse Mills ratio. From this we can calculate the expected value for those households that are participating i.e. has passed the first hurdle 


$$
\begin{aligned}
E\left(y_{i t} \mid y_{1 i t}^{*}>0, x_{i t}\right) & =P\left(y_{2 i t}^{*}>0 \mid y_{1 i t}^{*}>0, x_{i t}\right) \cdot E\left(y_{i t} \mid y_{i t}>0, x_{i t}\right) \\
& =\Phi\left(\frac{x \beta}{\sigma}\right)\left(x \beta+\sigma \cdot \lambda\left(\frac{x \beta}{\sigma}\right)\right)
\end{aligned}
$$

The partial effects for a continuous variable is:

$$
\frac{\partial E\left(y_{i t} \mid y_{1 i t}^{*}>0, x_{i t}\right)}{\partial x_{k}}=\varphi\left(\frac{x \beta}{\sigma}\right) \cdot \beta \cdot\left(\frac{x \beta}{\sigma}+\lambda\left(\frac{x \beta}{\sigma}\right)\right)+\Phi\left(\frac{x \beta}{\sigma}\right) \cdot \beta\left(1-\lambda\left(\frac{x \beta}{\sigma}\right)\left(\beta x+\sigma \cdot \lambda\left(\frac{x \beta}{\sigma}\right)\right)\right)
$$

And for a discrete variable

$$
\frac{\partial E\left(y_{i t} \mid y_{1 i t}^{*}>0, x_{i t}\right)}{\partial x_{k}}=\Phi\left(\frac{x \beta^{1}}{\sigma}\right)\left(x \beta^{1}+\sigma \cdot \lambda\left(\frac{x \beta^{1}}{\sigma}\right)\right)-\Phi\left(\frac{x \beta^{0}}{\sigma}\right)\left(x \beta^{0}+\sigma \cdot \lambda\left(\frac{x \beta^{0}}{\sigma}\right)\right)
$$

Where $x \beta^{1}=x_{1} \beta_{1}+\ldots+x_{k-1} \beta_{k-1}+1 \cdot \beta_{k}$ and $x \beta^{0}=x_{1} \beta_{1}+\ldots+x_{k-1} \beta_{k-1}+0 \cdot \beta_{k} \cdot w \alpha^{0}$ and $w \alpha^{1}$ are defined above.

The unconditional expected value can be calculated as:

$E\left(y_{i t} \mid x_{i t}, w_{i t}\right)=P\left(y_{i t}>0 \mid x_{i t}, w_{i t}\right) E\left(y_{i t} \mid y_{i t}>0, x_{i t}\right)=\Phi(w \alpha) \Phi\left(\frac{x \beta}{\sigma}\right)\left(x \beta+\sigma \cdot \lambda\left(\frac{x \beta}{\sigma}\right)\right)$ and the partial effects for a continuous variable as:

$$
\begin{aligned}
\frac{\partial E\left(y_{i t} \mid w_{i t}, x_{i t}\right)}{\partial x_{k}} & =\left(\alpha_{k} \phi(w \alpha) \Phi\left(\frac{x \beta}{\sigma}\right)+\frac{\beta_{k}}{\sigma} \phi\left(\frac{x \beta}{\sigma}\right) \Phi(w \alpha)\right)\left(x \beta+\sigma \cdot \lambda\left(\frac{x \beta}{\sigma}\right)\right) \\
& +\Phi(w \alpha) \Phi\left(\frac{x \beta}{\sigma}\right) \beta_{k}\left[1-\lambda\left(\frac{x \beta}{\sigma}\right)\left(x \beta+\sigma \cdot \lambda\left(\frac{x \beta}{\sigma}\right)\right)\right]
\end{aligned}
$$

And for a discrete variable

$$
\frac{\partial E\left(y_{i t} \mid w_{i t}, x_{i t}\right)}{\partial x_{k}}=\Phi\left(w \alpha^{1}\right) \Phi\left(\frac{x \beta^{1}}{\sigma}\right)\left(x \beta^{1}+\sigma \cdot \lambda\left(\frac{x \beta^{1}}{\sigma}\right)\right)-\Phi\left(w \alpha^{0}\right) \Phi\left(\frac{x \beta^{0}}{\sigma}\right)\left(x \beta^{0}+\sigma \cdot \lambda\left(\frac{x \beta^{0}}{\sigma}\right)\right)
$$

\begin{tabular}{|c|c|c|c|c|c|c|}
\hline & Convinced & Positive and food inv. & Positive and conv. & Product focussed & Indifferent & Sceptics \\
\hline \multirow[t]{2}{*}{ Pest_dir } & 0.1021 & 0.0932 & 0.0609 & 0.0430 & 0.0417 & 0.0207 \\
\hline & $(0.000)$ & $(0.0000)$ & $(0.0050)$ & $(0.0000)$ & $(0.0052)$ & $(0.0654)$ \\
\hline \multirow[t]{2}{*}{ Pest_indir } & 0.0218 & 0.0174 & 0.0113 & 0.0049 & 0.0059 & 0.0029 \\
\hline & $(0.001)$ & $(0.0000)$ & $(0.0186)$ & $(0.0335)$ & $(0.1000)$ & $(0.2611)$ \\
\hline \multirow[t]{2}{*}{ Pest_dir-1 } & 0.0332 & -0.0464 & -0.0087 & 0.0114 & -0.0028 & -0.0205 \\
\hline & $(0.4609)$ & $(0.1089)$ & $(0.8168)$ & $(0.5132)$ & $(0.9226)$ & $(0.3338)$ \\
\hline \multirow[t]{2}{*}{ Pest_indir -1} & -0.0057 & 0.0077 & 0.0004 & -0.0026 & -0.0008 & 0.0014 \\
\hline & $(0.2375)$ & $(0.0140)$ & $(0.9265)$ & $(0.1798)$ & $(0.7915)$ & $(0.5194)$ \\
\hline \multirow[t]{2}{*}{ Health_dir } & 0.0361 & 0.0214 & -0.0122 & 0.0053 & 0.0073 & 0.0076 \\
\hline & $(0.0092)$ & $(0.0216)$ & $(0.3303)$ & $(0.3770)$ & $(0.4313)$ & $(0.2597)$ \\
\hline \multirow[t]{2}{*}{ Health_indir } & -0.0141 & -0.0065 & -0.0042 & -0.0036 & -0.0044 & -0.0025 \\
\hline & $(0.0000)$ & $(0.0000)$ & $(0.0477)$ & $(0.0006)$ & $(0.0071)$ & $(0.0303)$ \\
\hline \multirow[t]{2}{*}{ Health_dir ${ }_{-1}$} & -0.0103 & -0.0126 & -0.0091 & -0.0075 & -0.0153 & -0.0104 \\
\hline & $(0.4408)$ & $(0.1605)$ & $(0.4448)$ & $(0.1960)$ & $(0.0954)$ & $(0.1183)$ \\
\hline \multirow[t]{2}{*}{ Health_indir ${ }_{-1}$} & 0.0012 & 0.0011 & 0.0010 & -0.0009 & -0.0015 & -0.0005 \\
\hline & $(0.5333)$ & $(0.3922)$ & $(0.5788)$ & $(0.2761)$ & $(0.2621)$ & $(0.6225)$ \\
\hline \multirow[t]{2}{*}{ Monthly exp } & 0.0331 & 0.0148 & 0.0088 & 0.0055 & 0.0039 & 0.0069 \\
\hline & $(0.0000)$ & $(0.0000)$ & $(0.0312)$ & $(0.0062)$ & $(0.1856)$ & (0.0016) \\
\hline
\end{tabular}

Where $x \beta^{1}, x \beta^{0}, w \alpha^{0}$ and $w \alpha^{1}$ are defined above.

\section{Appendix C. Calculated Average Partial Effects}

Table $\mathrm{C} 1$. Partial effects for first hurdle $\mathrm{dP}[\mathrm{y}>0] / \mathrm{dx}$, (probability values in parenthesis). Bold indicate significant at $5 \%$ level 
Table C2. Conditional partial effects for second hurdled $\mathrm{E}[\mathrm{y} \mid \mathrm{y}>0] / \mathrm{dX}$, (probability values in parenthesis). Bold indicate significant at $5 \%$ level

\begin{tabular}{lllllll}
\hline & Convinced & Positive and food inv. & Positive and conv. & Product focussed & Indifferent & Sceptics \\
\hline Pest_dir & 0.0302 & 0.0090 & -0.0369 & 0.0132 & $\mathbf{- 0 . 0 9 9 4}$ & -0.0061 \\
& $(0.1279)$ & $(0.5926)$ & $(0.1552)$ & $(0.5078)$ & $(0.0498)$ & $(0.8281)$ \\
Pest_indir & 0.0014 & -0.0019 & -0.0050 & $\mathbf{- 0 . 0 1 2 6}$ & 0.0030 & -0.0049 \\
& $(0.7616)$ & $(0.6228)$ & $(0.3648)$ & $(0.0290)$ & $(0.7572)$ & $(0.3955)$ \\
Pest_dir-1 & 0.0089 & -0.0386 & -0.0398 & -0.0135 & $\mathbf{- 0 . 2 6 2 0}$ & -0.0634 \\
& $(0.8014)$ & $(0.2149)$ & $(0.3691)$ & $(0.6854)$ & $(0.0062)$ & $(0.2667)$ \\
Pest_indir-1 & 0.0018 & 0.0043 & -0.0028 & 0.0030 & 0.0140 & 0.0009 \\
& $(0.6513)$ & $(0.1904)$ & $(0.5564)$ & $(0.4367)$ & $(0.1267)$ & $(0.8773)$ \\
Health_dir & 0.0136 & 0.0060 & 0.0034 & -0.0116 & -0.0478 & 0.0122 \\
& $(0.2489)$ & $(0.5394)$ & $(0.8147)$ & $(0.3242)$ & $(0.0955)$ & $(0.5128)$ \\
Health_indir & $\mathbf{0 . 0 0 5 2}$ & $\mathbf{0 . 0 0 7 7}$ & $\mathbf{0 . 0 0 7 4}$ & $\mathbf{0 . 0 1 1 0}$ & $\mathbf{0 . 0 1 8 6}$ & $\mathbf{0 . 0 0 8 6}$ \\
& $(0.0094)$ & $(0.0000)$ & $(0.0022)$ & $(0.0001)$ & $(0.0008)$ & $(0.0055)$ \\
Health_dir-1 & 0.0143 & 0.0130 & 0.0094 & $\mathbf{- 0 . 0 4 1 0}$ & 0.0494 & -0.0445 \\
& $(0.1881)$ & $(0.1848)$ & $(0.4942)$ & $(0.0058)$ & $(0.0594)$ & $(0.0525)$ \\
Health_indir-1 & -0.0005 & -0.0009 & -0.0018 & -0.0020 & 0.0027 & -0.0002 \\
& $(0.7554)$ & $(0.5358)$ & $(0.3709)$ & $(0.2599)$ & $(0.4673)$ & $(0.9314)$ \\
Relative price & $\mathbf{- 0 . 6 6 8 8}$ & $\mathbf{- 0 . 6 4 7 6}$ & $-\mathbf{0 . 7 4 1 7}$ & $\mathbf{- 0 . 8 6 2 9}$ & $\mathbf{- 0 . 6 2 3 8}$ & $\mathbf{- 0 . 8 8 9 3}$ \\
& $(0.0000)$ & $(0.0000)$ & $(0.0000)$ & $(0.0000)$ & $(0.0424)$ & $(0.0000)$ \\
Monthly exp & $\mathbf{0 . 0 2 3 4}$ & $\mathbf{0 . 0 0 9 1}$ & 0.0040 & -0.0081 & -0.0019 & -0.0010 \\
& $(0.0000)$ & $(0.0071)$ & $(0.3831)$ & $(0.0726)$ & $(0.8177)$ & $(0.8554)$ \\
\hline
\end{tabular}

Table C3. Unconditional partial effects for second hurdle $\mathrm{dE}[\mathrm{y}] / \mathrm{dX}$, (probability values in parenthesis). Bold indicate significant at 5\% level

\begin{tabular}{|c|c|c|c|c|c|c|}
\hline & Convinced & Positive and food inv. & Positive and conv. & Product focussed & Indifferent & Sceptics \\
\hline \multirow[t]{2}{*}{ Pest_dir } & 0.0553 & 0.0312 & 0.0328 & 0.0123 & 0.0041 & 0.0042 \\
\hline & $(0.0000)$ & $(0.0000)$ & $(0.0006)$ & $(0.0001)$ & $(0.4381)$ & $(0.1311)$ \\
\hline \multirow[t]{2}{*}{ Pest_indir } & 0.0097 & 0.0049 & 0.0026 & 0.0000 & 0.0018 & 0.0003 \\
\hline & $(0.0011)$ & $(0.0005)$ & $(0.2007)$ & $(0.9957)$ & $(0.1114)$ & $(0.5899)$ \\
\hline \multirow[t]{2}{*}{ Pest_dir ${ }_{-1}$} & 0.0176 & -0.0239 & -0.0129 & 0.0005 & -0.0202 & -0.0084 \\
\hline & $(0.4447$ & $(0.0349)$ & $(0.4330)$ & $(0.9268)$ & $(0.0446)$ & $(0.1167)$ \\
\hline \multirow[t]{2}{*}{ Pest_indir ${ }_{-1}$} & -0.0016 & 0.0035 & -0.0006 & -0.0005 & 0.0008 & 0.0004 \\
\hline & $(0.5184)$ & $(0.0045)$ & $(0.7527)$ & $(0.4449)$ & $(0.4285)$ & $(0.5044)$ \\
\hline \multirow[t]{2}{*}{ Health_dir } & 0.0208 & 0.0081 & 0.0004 & 0.0007 & -0.0016 & 0.0024 \\
\hline & $(0.0046)$ & $(0.0244)$ & $(0.6772)$ & $(0.7269)$ & $(0.6180)$ & (0.1599) \\
\hline \multirow[t]{2}{*}{ Health_indir } & -0.0036 & -0.0002 & -0.0001 & 0.0002 & 0.0002 & 0.0000 \\
\hline & $(0.0036)$ & $(0.7928)$ & $(0.8918)$ & $(0.5397)$ & $(0.7670)$ & $(0.9609)$ \\
\hline \multirow[t]{2}{*}{ Health_dir ${ }_{-1}$} & 0.0019 & -0.0007 & -0.0008 & -0.0051 & -0.0005 & -0.0050 \\
\hline & $(0.7866)$ & $(0.8331)$ & $(0.8732)$ & $(0.0124)$ & $(0.8599)$ & $(0.0074)$ \\
\hline \multirow[t]{2}{*}{ Health_indir ${ }_{-1}$} & 0.0003 & 0.0001 & -0.0001 & -0.0003 & -0.0002 & -0.0001 \\
\hline & $(0.7798)$ & $(0.7805)$ & $(0.8918)$ & $(0.2210)$ & $(0.6392)$ & $(0.6186)$ \\
\hline \multirow[t]{2}{*}{ Relative price } & -0.2882 & -0.1581 & -0.1445 & -0.0225 & -0.0463 & -0.0546 \\
\hline & $(0.0000)$ & $(0.0000)$ & $(0.0000)$ & $(0.0000)$ & $(0.0318)$ & $(0.0000)$ \\
\hline \multirow[t]{2}{*}{ Monthly exp } & 0.0101 & 0.0022 & 0.0010 & -0.0008 & -0.0001 & -0.0001 \\
\hline & $(0.0000)$ & $(0.0059)$ & $(0.3765)$ & $(0.0718)$ & $(0.8074)$ & $(0.8463)$ \\
\hline
\end{tabular}

